\title{
Comparative thermoeconomic analyses and multi-objective particle swarm optimization of geothermal combined cooling and power systems
}

${ }^{a}$ School of Mechanical Engineering, College of Engineering, University of Tehran, P.O. Box 11155-4563, Tehran, Iran

${ }^{b}$ Department of Mechanical Engineering, Faculty of Engineering and Technology, Alzahra University, Tehran, Iran

${ }^{c}$ Clean Energy Processes (CEP) Laboratory, Department of Chemical Engineering, Imperial College London, London SW7 2AZ, U.K. * Corresponding author: c.markides@imperial.ac.uk

8 N.B.: This is the PREPRINT (Accepted) version of this article. The final, published version of the article

9 can be found at: https://doi.org/10.1016/j.enconman.2021.113921

10 Abstract

11 Comparative parametric and multi-objective optimization analyses of three novel geothermal systems

12 are performed for combined cooling and power generation. The first (Configuration (a)) consists of an

13 absorption power cycle and an ejector refrigeration cycle, the second (Configuration (b)) of a modified

14 Kalina cycle and an absorption refrigeration cycle, and the third (Configuration (c)) of a double-flash

15 power cycle and an ejector refrigeration cycle, in all cases for power generation and cooling,

16 respectively. Both thermodynamic (energy, exergy) and economic criteria are compared to gain an

17 understanding of the characteristics and performance of these systems, and to ascertain the most

18 appropriate system for different scenarios. Results from the parametric study show that

19 Configuration (a) has the highest power output and exergy efficiency, but lowest cooling capacity and

20 overall (power plus cooling) thermal efficiency, while Configuration (b) has the highest cooling

21 capacity and thermal efficiency, but lowest power output and exergy efficiency. From an

22 exergoeconomic perspective, Configuration (a) has the lowest and Configuration (b) the highest total

23 specific cost. Configuration (c) maintains, generally, a thermoeconomic performance in-between those

24 of the other two systems. The optimization results indicate that if the thermal efficiency and total

25 specific cost are considered competing objectives over a range of well conditions, the optimal solutions

26 obtained by the LINMAP method for Configurations (a) to (c) have thermal efficiencies of 19.1\%, $2743.0 \%, 42.4 \%$, exergy efficiencies of $57.6 \%, 23.6 \%, 33.1 \%$, total cost rates of $436 \$ / \mathrm{h}, 558 \$ / \mathrm{h}$, $28596 \$ / \mathrm{h}$, and total specific costs of $29.7 \$ / G J, 66.9 \$ / G J, 43.5 \$ / G J$. If the exergy efficiency and total 29 cost rate are considered competing objectives, the corresponding values are $13.0 \% / 29.1 \% / 10.5 \%$, $3067.3 \% / 30.5 \% / 37.3 \%, 362 / 353 / 384 \$ / h$, and 24.9/67.5/42.7\$/GJ, respectively.

31 Keywords: absorption power, combined cooling and power, ejector refrigeration, geothermal, 32 multi-objective optimization, thermoeconomic analysis 


\begin{tabular}{|c|c|c|c|}
\hline \multicolumn{4}{|c|}{ Nomenclature } \\
\hline$A$ & Area, $\mathrm{m}^{2}$ & $\mathrm{CCP}$ & Combined cooling and power \\
\hline$c$ & Specific exergy cost, $\$ / \mathrm{J}$ & CHP & Combined heat and power \\
\hline$\dot{C}$ & Cost rate, $\$ / \mathrm{h}$ & $\mathrm{CI}$ & Capital investment \\
\hline$d$ & Borehole depth of geothermal well, $\mathrm{m}$ & com & Compressor \\
\hline$D$ & Diameter, $\mathrm{m}$ & con & Condenser \\
\hline$f$ & Exergoeconomic factor & CRF & Capital recovery factor \\
\hline$\dot{E}$ & Exergy rate, $\mathrm{W}$ & crit & Critical \\
\hline$E D$ & Euclidean distance & $\mathrm{CS}$ & Cooling set \\
\hline$h$ & Specific enthalpy, J/kg & $\mathrm{D}$ & Destruction \\
\hline$i$ & Interest rate & diff & Diffuser \\
\hline$\dot{m}$ & Mass flow rate, $\mathrm{kg} / \mathrm{s}$ & eje & Ejector \\
\hline$n$ & Number of operating years & EV & Expansion valve \\
\hline$P$ & Pressure, $\mathrm{Pa}$ & eva & Evaporator \\
\hline$P R$ & Pressure ratio & $\mathrm{F}$ & Fuel \\
\hline$\dot{Q}$ & Heat transfer rate, $\mathrm{W}$ & geo & Geothermal \\
\hline$R_{C}$ & Relative closeness & GWP & Global warming potential \\
\hline$s$ & Specific entropy, J/kg K & HE & Heat exchanger \\
\hline$T$ & Temperature, ${ }^{\circ} \mathrm{C}$ or $\mathrm{K}$ & in & Inlet \\
\hline$U$ & Heat transfer coefficient, $\mathrm{W} / \mathrm{m}^{2} \mathrm{~K}$ & ip & Inlet pipe \\
\hline$V$ & Volume, $\mathrm{m}^{3}$ & is & Isentropic \\
\hline$w$ & Weighting coefficient & $k$ & $k^{\text {th }}$ component \\
\hline$\dot{W}$ & Power, W & $\mathrm{L}$ & Loss \\
\hline$x$ & Quality & $\operatorname{mix}$ & Mixer \\
\hline$X$ & Mass fraction, $\%$ & MF & Mixed fluid \\
\hline$Z$ & Investment cost, \$ & MOPSO & Multi-objective particle swarm optimization \\
\hline$\dot{Z}$ & Cost rate of components, $\$ / \mathrm{h}$ & $\mathrm{N}$ & Normalized \\
\hline$Z_{\text {drill }}$ & Drilling cost, $\$$ & noz & Nozzle \\
\hline$Z_{\mathrm{SI}}$ & Surface installation cost, $\$$ & ODP & Ozone depletion potential \\
\hline$\dot{Z}^{\mathrm{CI}}$ & $\begin{array}{l}\text { Capital investment cost rate of } \\
\text { components, } \$ / \mathrm{h}\end{array}$ & $\mathrm{OM}$ & Operating and maintenance \\
\hline
\end{tabular}




\begin{tabular}{|c|c|c|c|}
\hline$\dot{Z}^{\mathrm{OM}}$ & $\begin{array}{l}\text { Operating and maintenance cost rate } \\
\text { of components, } \$ / \mathrm{h}\end{array}$ & out & Outlet \\
\hline \multicolumn{2}{|c|}{ Greek letters } & $\mathrm{pu}$ & Pump \\
\hline$\varepsilon$ & Heat exchanger efficiency & $\mathrm{P}$ & Product \\
\hline$\zeta$ & Geothermal gradient, ${ }^{\circ} \mathrm{C} / \mathrm{m}$ & PP & Pinch point \\
\hline$\eta_{\mathrm{ex}}$ & Exergy efficiency, \% & $\mathrm{PF}$ & Primary fluid \\
\hline$\eta_{\text {th }}$ & Thermal efficiency, $\%$ & Q & Heat \\
\hline$\eta$ & Efficiency, \% & ref & Reference \\
\hline$\theta$ & Correction coefficient & SHE & Solution heat exchanger \\
\hline$\rho$ & Density, $\mathrm{kg} / \mathrm{m}^{3}$ & SI & Surface installation \\
\hline$\tau$ & Annual plant operation hours, $\mathrm{h}$ & $\mathrm{SF}$ & Secondary fluid \\
\hline$\varphi$ & Maintenance factor & SP & Separator \\
\hline \multicolumn{2}{|c|}{ Subscripts, superscripts and abbreviations } & tu & Turbine \\
\hline 0 & Dead state & tot & Total \\
\hline abs & Absorber & va & Valve \\
\hline $\mathrm{b}$ & Booster & VG & Vapour generator \\
\hline CEPCI & $\begin{array}{l}\text { Chemical Engineering Plant Cost } \\
\text { Index }\end{array}$ & $\mathrm{W}$ & Work \\
\hline
\end{tabular}

33 


\section{Introduction}

35 Geothermal energy has some crucial advantages relative to other renewable energy sources,

36 including primarily its capacity to drive continuous system operation with high capacity factors, reduced operational variability and need for storage. Geothermal cogeneration systems have appeared as particularly promising alternatives to fossil-fuel power plants in this context, owing to their unique potential to deliver multiple useful energy vectors at higher overall efficiencies than separate, standalone systems, and been studied extensively. Specific interest, especially in global regions with warmer climates, exists in the cogeneration of combined cooling and power (CCP).

Many researchers have investigated conventional geothermal plants and proposed novel geothermal systems based on various cycles and configurations thereof [1]. The selection of a suitable working fluid is of primary importance in organic Rankine cycle (ORC) systems, which is a particularly popular cycle in these applications, leading Zare [2] to consider different fluids for such systems when utilizing medium-grade geothermal brine. Isobutane was identified as a particularly suitable working fluid in this study when considering both thermodynamic and economic performance indicators. In another study, Altun and Kilic [3] evaluated the thermodynamic performance of a geothermal ORC system and reported that the exergy efficiency of the system can be as high as $39 \%$ if this is designed appropriately.

Other cycles and configurations have also been proposed for use in geothermal applications, e.g., single- and double-flash binary cycles. Yari [4] evaluated different geothermal power plants considering various configurations based on energy and exergy analyses. The author concluded that the double-flash binary system can in some cases show improved performance relative to conventional ORC systems, in terms of thermal and exergy efficiencies. In addition to ORC and flash cycles, Kalina systems have also shown comparable performance in applications involving lower-grade geothermal sources. In this regard, Fiaschi et al. [5] assessed the performance of a Kalina-based geothermal system and compared the performance of such a system to equivalent ORC systems. They reported that Kalina systems can produce $22-42 \%$ more power compared to ORC systems, although this conclusion does not include considerations of system

62 power cycles can outperform conventional Rankine cycles in terms of efficiency and power output, 63 i.e., again in the absence of economic considerations. In any case, from studies such as these, there 
64 is evidence that $\mathrm{LiBr}$-water absorption power cycles can be employed as a promising alternative

65 to conventional Rankine and Kalina systems when geothermal sources are used.

Of particular interest to the present research are multigeneration geothermal systems. Such systems have important advantages when used in residential and industrial applications, due to the higher overall energy generation and their ability to cater to the holistic energy demands of endusers, which invariably involve multiple energy vectors. Van Erdeweghe [7] compared the performance of a range of different low-grade geothermal combined heat and power (CHP) systems with ORC technology for heat-to-power conversion. The results from this study indicated that the second-law efficiency of such CHP systems can be up to $23 \%$ higher than that of conventional (power-generating only) geothermal plants. Similarly, Kalina cycle systems have shown great functionality after being integrated with geothermal systems for multigeneration purposes. Zare [8] compared the performance of trigeneration systems featuring Kalina cycles when utilizing low-grade geothermal sources from a thermodynamic standpoint. Results revealed that for a low-temperature geothermal brine temperature of $120^{\circ} \mathrm{C}$, the Kalina cycle-based system might produce $12 \%$ higher electricity compared to conventional ORC systems.

Among multigeneration systems, geothermal CCP systems are prominent in industrial and residential applications. Motivated by the knowledge that Kalina cycles have shown promising performance when utilizing low-grade heat sources, Cao et al. [9] investigated a Kalina system internally integrated with an absorption refrigeration system driven by low-grade geothermal heat source for cooling and power. This work showed that the second-law efficiency and power generation capability of this system can exceed that of standalone systems. Zhao et al. [10] investigated another type of geothermal CCP system, this time incorporating an ORC system and an ejector refrigeration cycle through internal integration and indicated that ejectors are suitable for flexible integration with ORC systems. The aforementioned studies focused on the thermodynamic performance of geothermal CCP systems, without economic considerations, but other studies have investigated the systems from a thermoeconomic standpoint, including a Kalina [11] and a

90 geothermal cascade system [12]. Fiaschi et al. [5], for example, investigated the economic 91 performance of Kalina- and ORC-based systems driven by geothermal heat sources. These authors 92 reported that the specific cost of electricity associated with ORC systems is a little lower (by 3\%), 93 which aligns with knowledge in other applications of these two technologies. In all cases, the heat94 source temperature is identified as a crucial parameter that affects the thermodynamic and economic 
95 performance of such systems. Accordingly, the impact of the geothermal heat source on the 96 thermoeconomic performance of binary-cycle geothermal plants was assessed by Liu et al. [13], who 97 concluded that an elevated geothermal brine temperature, leads to an increase in all objective 98 functions, i.e., capital cost, power generation, and second law efficiency.

99 Even though numerous studies have been performed on proposing and investigating 100 multigeneration geothermal systems from exergetic [14], economic [15] and 101 thermal/thermoeconomic [16] standpoints, less research has been dedicated to optimizing the 102 proposed multigeneration and/or conventional geothermal systems. Nevertheless, some 103 excellent studies have been published in this space, especially more recently. Van Erdeweghe et $104 a l$. [17] performed design optimization of different system configurations in off-design operation 105 and reported improved economics when using multiple configurations as well as improved 106 geothermal energy-source utilization relative to electrical power plants. Based on their results, 107 they described an optimal binary geothermal CHP system configuration. In another similar study 108 [18], the same authors optimized geothermal-based ORC systems while considering off-design 109 operation and performance. They found that a crucial parameter that significantly affects the 110 performance of such systems is the turbine inlet pressure; crucial parameters such as this should 111 be considered when such systems are optimized. Furthermore, optimization which takes into 112 account economic criteria is increasingly necessary as economic issues are important to many 113 stakeholders. For this reason, thermoeconomic optimization with interesting findings was 114 considered in Ref. [19] for a flash binary geothermal system and further in Ref. [20] for various 115 flash binary enhanced geothermal system configurations.

Nevertheless, few studies to date have focused on the optimization of geothermal systems 117 using a multi-objective optimization [21]. Of particular relevance here is the work of Clarke and 118 McLeskey [22], who conducted multi-objective optimization of binary geothermal power-plant 119 systems and concluded that multi-objective swarm optimization is a preferred approach to other 120 algorithms for the optimization of these systems. Even less attention has been paid to the multi121 objective optimization of geothermal multigeneration systems [23]. On the other hand, although 122 multi-objective optimization of such systems considering various objective functions, e.g., 123 efficiency and cost, can help identify suitable system designs for different decision-makers, only 124 a handful of studies have undertaken such multi-objective optimization of geothermal systems 
125 considering both thermodynamic and thermoeconomic viewpoints focusing on the selection of 126 working fluids [24] and conventional geothermal systems [25].

127 Despite the wide interest and significant work overall into geothermal energy systems, 128 multi-objective optimization studies of geothermal multigeneration systems are scarce in the 129 literature. To the best of the authors' knowledge, most of the research reported in the literature 130 relates to energy and exergy analyses of multigeneration geothermal systems, with few studies 131 focusing on economic criteria and overall system optimization with respect to a variety of technical 132 or economic performance indicators or metrics. It is noteworthy, in particular, that almost no 133 attention has been paid to the multi-objective optimization of multigeneration geothermal systems 134 considering thermodynamic and thermoeconomic aspects.

135 In this study, three novel cogeneration geothermal systems are proposed and then analysed comprehensively from both thermodynamic and economic perspectives, extending to optimizing

137 the proposed systems by implementing the multi-objective particle swarm optimization in order to 138 maximize a selection of objective functions while minimizing cost. In summary, the primary objectives of the present study are:

- to propose and investigate comprehensively three novel geothermal CCP systems, each based on different technologies and configuration;

- to apply energy, exergy and thermoeconomic analyses to the proposed configurations;

\section{Selection and description of proposed system configurations}

149 Absorption power cycles are power generation systems in which a vapour generator, heat 150 exchanger, expansion valve, absorber, pump and turbine are employed (see Fig. 1(a), and Fig. 2(a) 151 excluding the components covered by dashed lines) [26], whereas Kalina cycle systems (see 152 Fig. 1(b), and Fig. 2(b) excluding the components covered by dashed lines) [27] and double-flash

153 binary cycle systems are more conventional power generation systems (see Fig. 1(c), and Fig 2(c) 
154 excluding the components covered by dash lines) [4]. According to the literature, absorption power 155 [6], Kalina [8] and double-flash binary [4] systems are the preferred and most widely considered 156 technologies employed when low- to medium-grade geothermal heat sources are to be utilized (via 157 conversion) for power generation, along with ORC systems.

Furthermore, absorption chiller [12] and ejector refrigeration cycle [10] systems are conventional cooling systems that can be either internally or externally combined with various power generation systems (see the cycles covered by dashed lines in Fig. 1). Ejector refrigeration cycles have shown good performance when low temperature waste heat is available [28], and are an excellent choice for internal integration with absorption power or double-flash binary systems wherein an (internal) low-temperature heat source can be provided for the ejector cooling system. Similarly, it has been reported that absorption cooling systems can be combined with other power generation cycles when sufficient waste heat is available [9], so a portion of the surplus heat from the vapour generator in a Kalina system can be used to drive an absorption chiller system, thus simultaneously generating power and supplying cooling. Ejector refrigeration cycles are a less suitable choice for integration with Kalina systems as sufficient waste heat is available in this case, for which absorption chiller systems have been reported to have better suitability [29].

Schematics of the three proposed geothermal CCP systems are shown in Fig. 1, and corresponding thermodynamic cycles associated with the proposed configurations are presented in

172 Fig. 2. The first system configuration (Configuration (a)) consists of an absorption power system 173 coupled to an ejector refrigeration cycle. Geothermal brine is fed to Vapour Generator 1 (Stream 1), 174 where it heats a $\mathrm{LiBr}$-water mixture, generating steam that passes to the turbine for power generation 175 (Stream 10) and a hot (weak) LiBr-water mixture solution (Stream 6) that is sent to Vapour Generator 1762 , which is used in the ejector refrigeration system. Downstream of this, the weak solution flows 177 through a solution heat exchanger (Stream 7), Expansion Valve 1 (Stream 8), and finally enters the 178 absorber (Stream 9) along with steam from the outlet of the turbine (Stream 11). Strong LiBr-water 179 solution after the absorber is sent to the pump (Stream 3), the solution heat exchanger (Stream 4), 180 and back to Vapour Generator 1 to be boiled by the geothermal brine. A refrigerant in the ejector 181 system is heated by the hot strong LiBr-water solution at the Vapour Generator 2 (Stream 15), before 182 entering the ejector as the primary fluid (Stream 16). The refrigerant leaves the evaporator toward 183 the booster, which is employed to increase pressure and enhance cooling performance (Stream 23). 
184 The compressed fluid is drawn in by the ejector where it mixes with the primary fluid (Stream 24).

185 The mixed fluid is then sent to the condenser (Stream 17), and a portion of it, after passing through

186 Expansion Valve 2 (Stream 19), is sent to the evaporator for cooling (Stream 20). The remaining

187 portion enters the pump for circulation back to the Vapour Generator 2 (Stream 14).

188 Configuration (b) comprises modified Kalina and absorption refrigeration cycles for 189 power generation and cooling. Saturated $\mathrm{NH}_{3}$-water (Streams 4 and 5) is pumped to the solution 190 heat exchanger and then the vapour generator (Stream 6). From there, ammonia vapour enters a 191 condenser (Stream 17), passes via an expansion valve (Stream 18) to the evaporator where it 192 absorbs heat and delivers cooling (Stream 19). The ammonia then mixes with weak $\mathrm{NH}_{3}$-water 193 solution in the absorber (Stream 20). The fluid leaving the vapour generator (Stream 7) enters 194 the heat exchanger where heat from the geothermal brine is utilized (Streams 1 and 2). The two195 phase flow (Stream 8) is then separated; the vapour phase (strong ammonia mixture) is sent to 196 the turbine (Stream 9), and the liquid phase (weak mixture) enters the solution heat exchanger 197 (Stream 11). The mixed fluid phase leaving the turbine and Expansion Valve 1 (Streams 10, 13 198 and 14) passes through the condenser and is sent back to the absorber (Streams 14, 15 and 16). Configuration (c) employs an ejector refrigeration cycle. Geothermal steam passes from an 200 expansion valve to Separator 1 (Streams 1 and 2), after which the liquid phase flows through a second 201 valve to Separator 2 (Streams 4 and 5) while the steam is sent via the turbine (Streams 3 and 6) to a 202 condenser (Stream 7). The liquid from Separator 2 enters the ejector as the primary flow (Stream 9), 203 entraining the secondary flow (Stream 15). The two-phase flow exiting the ejector enters a second 204 condenser where it rejects heat, and is split (Stream 10); a portion is sent to the reinjection well via a 205 pump (Stream 16), and the rest through Expansion Valve 3 (Stream 12) to the evaporator, where it 206 boils to provide cooling (Stream 13), the compressor, and finally the ejector (Streams 14 and 15). 

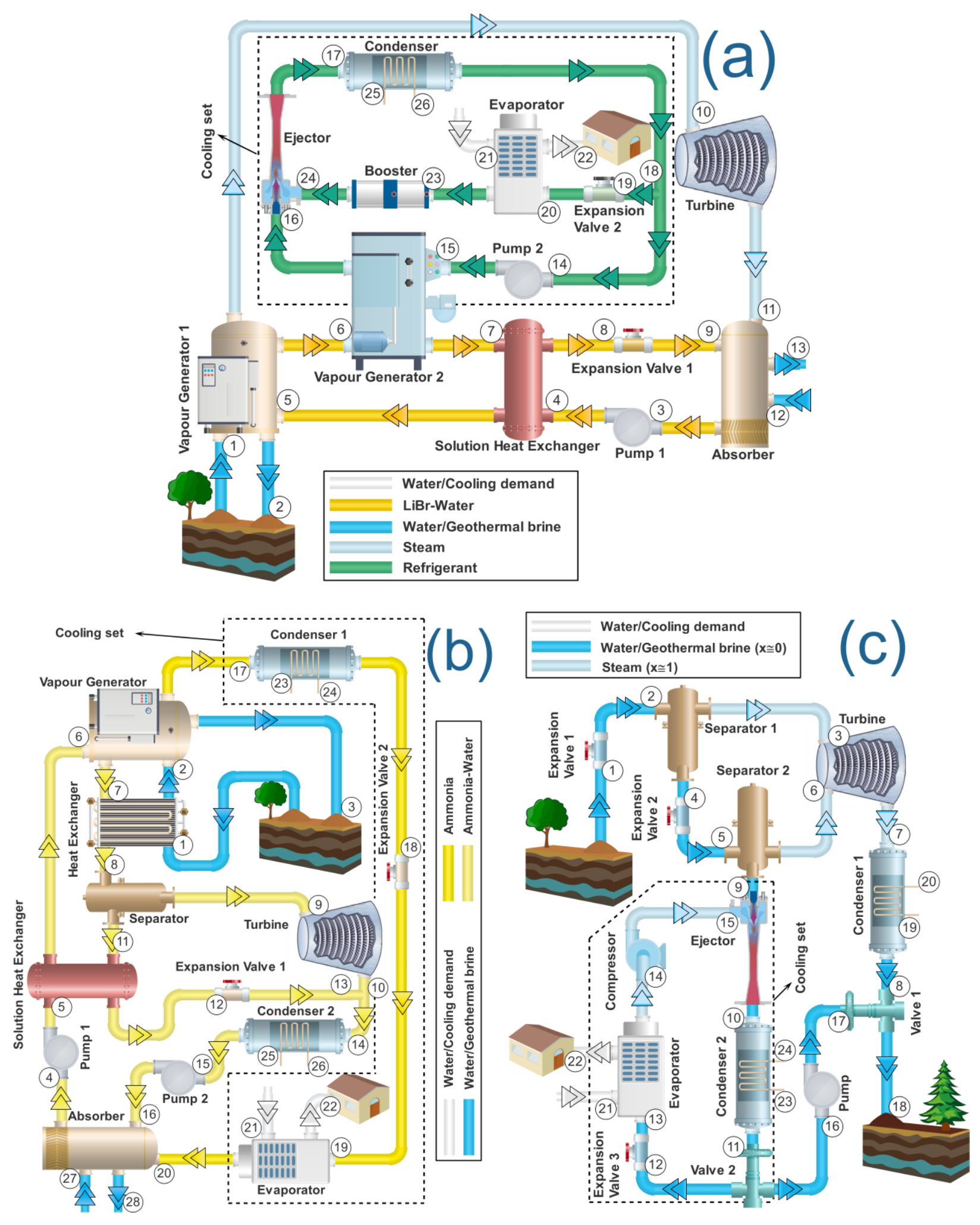

Figure 1: Proposed combined cooling and power (CCP) geothermal systems 

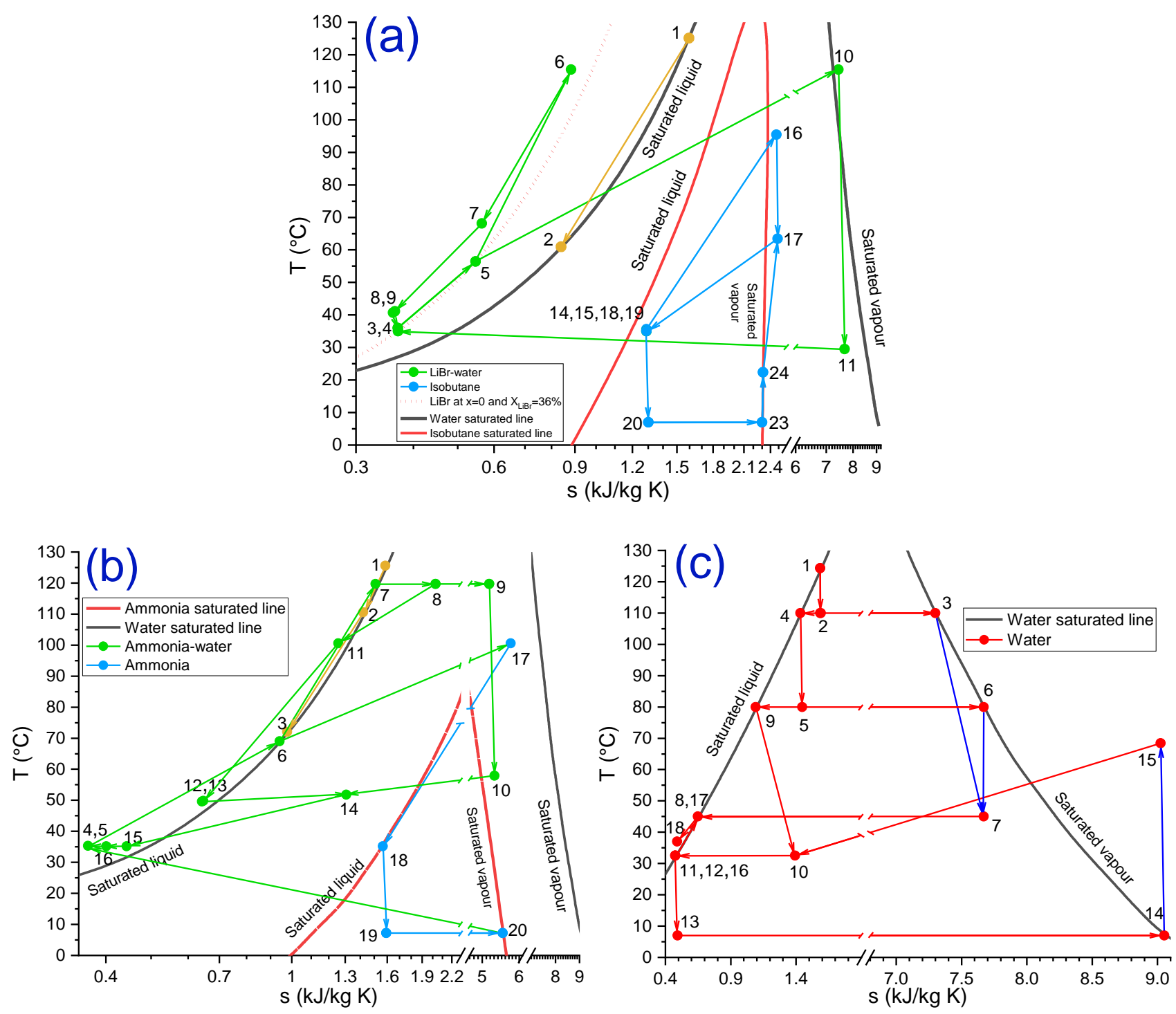

Figure 2: Thermodynamic cycles of the proposed system configurations on $T-s$ diagrams

\section{Methods}

216 The results from the assessments of the proposed CCP systems that are presented in this paper are

217 based on thermodynamic (energy and exergy) and economic analyses. The EES software

218 environment was used to solve thermodynamic relations, along with equations describing mass,

219 energy, exergy and cost conservation. The proposed systems were then optimized by linking EES

220 to MATLAB codes, and using a particle swarm optimization method. The detailed procedure and

221 corresponding mathematical modelling are described in this section. 
The following assumptions have been made in this work:

- steady-state conditions are assumed throughout;

- $\quad$ pressure drops within pipework are neglected;

- heat losses from all components to the ambient are neglected;

- kinetic and potential energy changes are neglected;

- outlets of all condensers, separators and evaporators are at saturated states;

and the models (including the assumptions) are validated against data in the literature in Section 4.1.

\subsection{Thermodynamic analysis}

First- (energy) and second-law (exergy) analyses were applied to each of the proposed system configurations using steady-state energy and exergy balance equations [30]:

$$
\begin{gathered}
\sum(\dot{m} h)_{\text {in }}-\sum(\dot{m} h)_{\text {out }}+\sum \dot{Q}_{\text {in }}-\sum \dot{Q}_{\text {out }}-\dot{W}=0 \\
\sum \dot{E}_{\text {in }}=\sum \dot{E}_{\text {out }}+\dot{E}_{\mathrm{D}}
\end{gathered}
$$

in which $\dot{m}, h, \dot{Q}, \dot{W}$, and $\dot{E}$ refer to mass flow rates, enthalpies, heat flow rates (or, heating loads), power (done by the system), and exergy rates. Subscripts 'in', 'out' and 'D' denote inlets, outlets, and destruction in the case of exergy rate. These two equations are applied to all components of the systems investigated in this work. The full list of component parameter values is given in Table 1.

The ejector is relatively more complicated than the other components in the systems under consideration in this work, so a brief description of the modelling of this component is provided here. The modelling of the ejector was conducted by following the methodology employed by Dai et al. [31]. This method is based on a one-dimensional (1-D) constant pressure approach that is widely used for ejector modelling, the fundamentals of which were developed by Huang et al. [32]. In addition, frictional losses were taken into account as neglecting such losses has been shown to reduce the reliability of the results [33]. The following assumptions, listed below, have been made specifically with regard to the modelling of this component [31]:

- $1-\mathrm{D}$ and steady-state conditions are assumed for the flow throughout the ejector;

- fluid velocities at the inlet and outlet of the ejector are ignored;

- frictional losses are accounted for via appropriate nozzle, diffuser and mixing section efficiencies;

- constant pressure is considered in the mixing section; 
- the ejector is insulated, so heat losses from the outer walls to the ambient are negligible.

After solving the set of energy balance equations throughout each CCP system configuration, including simulating the flow and thermodynamic processes through the ejector where relevant, the net work (in fact, power) output and cooling capacities/loads can be calculated

255 for each case. An overall (cooling plus power) thermal efficiency of each of the proposed systems 256 can then be calculated relative to the thermal energy taken from the geothermal heat source [4]:

$$
\eta_{\mathrm{th}}=\frac{\dot{W}_{\mathrm{net}}+\dot{Q}_{\mathrm{eva}}}{\dot{m}_{1}\left(h_{\mathrm{geo}, \text { in }}-h_{\text {geo,out }}\right)}
$$

258 in which $\dot{Q}_{\text {eva }}=\dot{m}_{21}\left(h_{22}-h_{21}\right)$ [34], and the subscripts 'eva', 'geo,in' and 'geo,out' denote the 259 evaporator, the geofluid inlet and the geofluid outlet, respectively.

Furthermore, an alternatively overall thermal efficiency definition is considered relative to the total thermal energy available in the geothermal heat source [4]:

$$
\eta_{\mathrm{th}}^{\prime}=\frac{\dot{W}_{\mathrm{net}}+\dot{Q}_{\mathrm{eva}}}{\dot{m}_{1}\left(h_{\mathrm{geo}, \mathrm{in}}-h_{0}\right)}
$$

where the subscript ' 0 ' denotes the dead state. Similarly, an exergy efficiency can be evaluated considering the exergy taken from the geothermal heat source [4]:

$$
\eta_{\text {ex }}=\frac{\dot{W}_{\text {net }}+\dot{E}_{\text {eva }}}{\dot{E}_{\text {geo,in }}-\dot{E}_{\text {geo,out }}}
$$

where $\dot{E}_{\text {eva }}=\dot{E}_{22}-\dot{E}_{21}[34]$, and an alternative exergy efficiency is also defined as [4]:

$$
\eta_{\text {ex }}^{\prime}=\frac{\dot{W}_{\text {net }}+\dot{E}_{\text {eva }}}{\dot{E}_{\text {geo,in }}}
$$

The first set of definitions is concerned with how effectively the systems can operate relative to the fractional energy/exergy taken from the heat source, whereas the second set of definitions is concerned with the effectiveness of the systems relative to the total (maximum)

272 In most results presented in this paper, specifically all results in Sections 4.3 to 4.5, Eqs. (3) and 273 (5) are used as the primary efficiency definitions of interest, however, results from those 274 definitions to results obtained with alternative efficiency definitions (i.e., Eqs. (4) and (6)) in 275 Section 4.6 are compared as well. The input conditions and all parameter values used for the simulation of all three CCP systems investigated in this work are summarized in Table 1. 
Table 1: Input parameters for the simulation of the proposed systems

\begin{tabular}{llll}
\hline Parameter & Value & Parameter & Value \\
\hline All configurations & & & \\
\hline Ambient temperature, $T_{0}$ & $20^{\circ} \mathrm{C}$ & Ambient pressure, $P_{0}$ & $101.3 \mathrm{kPa}$ \\
Borehole geothermal depth, $d$ & $3800 \mathrm{~m}[35]$ & Geothermal fluid temperature, $T_{\mathrm{geo}}$ & See $\underline{\text { Appendix A }}$ \\
Geothermal brine flow rate, $\dot{m}_{1}$ & $100 \mathrm{~kg} / \mathrm{s}[36]$ & Geothermal fluid pressure, $P_{1}$ & $750 \mathrm{kPa}$ \\
$\begin{array}{l}\text { Nozzle and diffuser efficiencies } \\
\text { of the ejectors, } \eta_{\mathrm{noz}}=\eta_{\text {diff }}\end{array}$ & $0.85[37]$ & $\begin{array}{l}\text { Temperature of the condensers and } \\
\text { absorbers, } T_{\text {con }}, T_{\text {abs }}\end{array}$ & $35^{\circ} \mathrm{C} \mathrm{[36]}$ \\
Turbines efficiency, $\eta_{\mathrm{tu}}$ & $0.85[36]$ & Mixing section efficiency of the ejectors, $\eta_{\text {mix }} 0.9[37]$ \\
Pumps efficiency, $\eta_{\mathrm{pu}}$ & $0.85[38]$ & Evaporators temperature, $T_{\mathrm{eva}}$ & $7{ }^{\circ} \mathrm{C}$ \\
\hline
\end{tabular}

Configuration (a)

Temperature difference between $\quad 10^{\circ} \mathrm{C}$ [39] $\quad$ Turbine inlet pressure, $P_{\text {in,tu }}$

$100 \mathrm{kPa}$

Streams 1 and $10, \Delta T_{\mathrm{VG} 1}$

Vapour Generator 2 pressure, $P_{\mathrm{VG} 2} 1300 \mathrm{kPa}$

$\mathrm{LiBr}$ mass fraction of Stream 3, $X_{\mathrm{LiBr}} \quad 36 \%$

Temperature difference between $3{ }^{\circ} \mathrm{C}$

Pressure ratio of the booster, $P R_{\mathrm{b}}$

$1.6[39]$

Streams 2 and $5, \Delta T_{\mathrm{VG} 1 \text {,hot }}$

Efficiency of the solution heat $\quad 0.83$ [40]

exchanger, $\varepsilon \mathrm{SHE}$

Pinch point temperature difference in the $3{ }^{\circ} \mathrm{C}$ evaporator and Vapour Generator 2,

$\Delta T_{\mathrm{PP}-\mathrm{VG} 2}, \Delta T_{\mathrm{PP}-\mathrm{eva}}$

\section{Configuration (b)}

Temperature difference between $10^{\circ} \mathrm{C}$ [39]

Streams 2 and 17, $\Delta T_{\mathrm{VG}}$

Efficiency of the solution heat

exchanger, $\varepsilon$ SHE
Temperature difference between

Streams 2 and 7, $\Delta T_{\text {hot,HE }}$

0.83 [40] Temperature difference between

Streams 1 and $2, \Delta T_{\mathrm{HE}}$
$10{ }^{\circ} \mathrm{C}[39]$

$15{ }^{\circ} \mathrm{C}$

\section{Configuration (c)}

Separator 1 pressure, $P_{\mathrm{SP} 1}$

$150 \mathrm{kPa}$

Condenser 2 pressure, $P_{\text {con2 }}$

$5 \mathrm{kPa}$

Separator 2 pressure, $P_{\mathrm{SP} 2}$

$50 \mathrm{kPa}$

Pressure ratio of the compressor, $P R_{\text {com }}$

2 [39]

Condenser 1 pressure, $P_{\text {con } 1}$

$10 \mathrm{kPa}$

Compressor efficiency, $\eta_{\mathrm{com}}$

0.85 [39]

\section{Exergoeconomic parameters}

Interest rate, $i$

0.12

Number of operating years, $n$

$20 \mathrm{yr}$ [36]

Annual operating hours, $\tau$

$330 \times 24 \mathrm{~h}$

Operating and maintenance factor, $\varphi$

$1.06[41]$ 


\subsection{Exergoeconomic analysis}

279 Exergoeconomic approaches are useful in assessing the economics of thermodynamic systems 280 such as those in the present study from an exergy-based (second law) perspective. In these 281 approaches, the cost flows, total cost rates and specific costs associated with all exergy flows 282 throughout the system are estimated, along with the cost of exergy destruction and 283 exergoeconomic factors, which are especially important economic performance indicators.

284 In performing this analysis, cost balance equations were first written for each component 285 ' $k$ ', as suggested in Ref. [42], in order to calculate the aforementioned factors:

$$
\sum \dot{C}_{\mathrm{out}, \mathrm{k}}+\dot{C}_{\mathrm{w}, k}=\sum \dot{C}_{\mathrm{in}, k}+\dot{C}_{\mathrm{q}, k}+\dot{Z}_{k}
$$

287

288

where $\dot{C}$ denotes the cost rate, and subscripts 'in', 'out', 'q' and 'w' refer to the inlet, outlet, heat and work.

The total cost rates of all components $\left(\dot{Z}_{k}\right)$ and flows were then obtained, respectively, from [42]:

$$
\begin{gathered}
\dot{Z}_{k}=\dot{Z}_{k}^{\mathrm{CI}}+\dot{Z}_{k}^{\mathrm{OM}} \\
\dot{C}_{m}=c_{m} \dot{E}_{m}
\end{gathered}
$$

for each component ' $k$ ', where superscript ' $\mathrm{CI}$ ' refers to capital investment, 'OM' to operating and maintenance expenses, and subscript ' $m$ ' can be replaced by 'in', 'out', 'w' or ' $q$ '.

Furthermore, the cost functions $\dot{Z}_{k}^{\mathrm{CI}}$ and $\dot{Z}_{k}$ were calculated from [42]:

$$
\begin{aligned}
& \dot{Z}_{k}^{\mathrm{CI}}=\left(\frac{C R F}{\tau}\right) Z_{k} \\
& \dot{Z}_{k}=\dot{Z}^{\mathrm{CI}} \times \varphi
\end{aligned}
$$

in which $\dot{Z}_{k}$ is the total cost rate of component ' $k$ ', including capital investment plus operating and maintenance cost rates. In addition, $\tau$ represents the annual operating hours excluding overhaul/repairing periods, $\varphi$ is the maintenance factor, which was taken as 1.06 in this study, and the capital recovery factor $(C R F)$ was found by considering inflation [42]:

$$
C R F=\frac{i(1+i)^{n}}{(1+i)^{n}-1}
$$

where $i$ is the interest rate, and $n$ is the number of working years (20 years for most such plants) [43]. 
The current costs of the components were then evaluated from [30]:

304 where the Chemical Engineering Plant Cost Index (CEPCI) adjusts values year to year.

305 Exergoeconomic parameters are calculated after solving the component cost balances $306 \quad[42,44]:$

312 where $c_{\mathrm{P}, k}, c_{\mathrm{F}, k}, \dot{C}_{\mathrm{P}, k}, \dot{C}_{\mathrm{F}, k}, \dot{C}_{\mathrm{D}, k}$ and $\dot{C}_{\mathrm{L}, k}$ are the unit product and fuel costs, cost rate of product and 313 fuel, exergy destruction and exergy loss cost rates of each component, and $f_{k}$ is the exergoeconomic 314 factor of component ' $k$ ', which provides a relative comparison of the total cost rate and cost of exergy 315 destruction and loss of that component. Further, $\dot{E}_{\mathrm{F}, k}$ and $\dot{E}_{\mathrm{F}, k}, \dot{E}_{\mathrm{D}, k}$ and $\dot{E}_{\mathrm{L}, k}$ denote the rate of exergy 316 of the products and fuels, the exergy destruction and the exergy loss for component $k$.

Finally, the systems were compared with respect to their exergoeconomic performance.

318 The cost balance equations, cost functions, and auxiliary equations required to perform the 319 comparison are listed in Appendix A, where the total cost rate of each system was evaluated from:

$$
\dot{C}_{\text {tot }}=\sum_{j=1}^{j=k} \dot{Z}_{j}
$$

321 and the total specific cost of each system in \$/GJ was evaluated from:

$$
c_{\mathrm{P}, \mathrm{tot}}=\frac{\dot{C}_{\mathrm{tot}}}{\left(\dot{W}_{\mathrm{net}}+\dot{E}_{\mathrm{eva}}\right) \times 0.0036}
$$

323 in which the factor 0.0036 in the nominator is added in order to convert $\$ / \mathrm{kWh}$ to $\$ / \mathrm{GJ}$. 


\section{$324 \quad 3.3 \quad$ Multi-objective particle swarm optimization}

325 All systems were optimized by considering multi-objective functions using MATLAB. The 326 decision variables used for the optimization are listed in Table 2. It should be noted that some 327 permutations are impossible, so they were neglected, and only possible and applicable 328 permutations were considered for the optimization.

329 Table 2: Constraints imposed on decision variables for multi-objective optimization

\begin{tabular}{|c|c|c|}
\hline Parameter & Constraint & Description \\
\hline \multicolumn{3}{|c|}{ All Configurations } \\
\hline$d(\mathrm{~m})$ & $3800-5000$ & $\begin{array}{l}\text { Heat source temperature limitation for the proposed systems, also drilling depth } \\
\text { limitation, the corresponding heat source temperature is } 125<T_{\text {geo }}\left({ }^{\circ} \mathrm{C}\right)<165\end{array}$ \\
\hline \multicolumn{3}{|c|}{ Configuration (a) } \\
\hline$\Delta T_{\mathrm{VG} 1}\left({ }^{\circ} \mathrm{C}\right)$ & $8-15$ & $\begin{array}{l}\text { Cold stream temperature cannot exceed the hot stream temperature in the } \\
\text { vapour generator }\end{array}$ \\
\hline$P_{\mathrm{VG} 2}(\mathrm{kPa})$ & $1200-1600$ & Vapour Generator 2 and ejector pressure limit \\
\hline$P_{\text {in,tu }}(\mathrm{kPa})$ & $50-110$ & Turbine inlet pressure limit which should be lower than the critical pressure \\
\hline$X_{\mathrm{LiBr}}(\%)$ & $20-37$ & $\mathrm{LiBr}$ mass fraction limitation for cooling and power \\
\hline$P R_{\mathrm{b}}$ & $1.2-1.6$ & Booster pressure ratio limited by the cooling set and ejector \\
\hline \multicolumn{3}{|c|}{ Configuration (b) } \\
\hline$\Delta T_{\mathrm{VG}}\left({ }^{\circ} \mathrm{C}\right)$ & $6-15$ & $\begin{array}{l}\text { Cold stream temperature cannot exceed hot stream temperature in the vapour } \\
\text { generator }\end{array}$ \\
\hline$\Delta T_{\mathrm{HE}}\left({ }^{\circ} \mathrm{C}\right)$ & $10-35$ & $\begin{array}{l}\text { Cold stream temperature cannot exceed hot stream temperature in the heat } \\
\text { exchanger }\end{array}$ \\
\hline$\Delta T_{\text {hot,HE }}\left({ }^{\circ} \mathrm{C}\right)$ & $7-20$ & $\begin{array}{l}\text { Cold stream temperature cannot exceed hot stream temperature in the heat } \\
\text { exchanger }\end{array}$ \\
\hline
\end{tabular}

\section{Configuration (c)}

\begin{tabular}{lll}
\hline$P R_{\text {com }}$ & $1.4-2.8$ & Compressor pressure ratio limited by the cooling set and ejector \\
$P_{\mathrm{SP} 1}(\mathrm{kPa})$ & $80-300$ & Separator 1 and turbine pressure limit to prevent the formation of liquid droplets \\
$P_{\mathrm{SP} 2}(\mathrm{kPa})$ & $20-70$ & Separator 2 pressure limit which should be lower than Separator 1 pressure \\
$P_{\text {con1 } 1}(\mathrm{kPa})$ & $8-15$ & Turbine outlet pressure limit to prevent the formation of liquid droplets \\
\hline
\end{tabular}
330

331 Multi-objective particle swarm optimization (MOPSO) was used to optimize the systems 332 through a dynamic weighted aggregation approach [45]. Particle swarm optimization (PSO) was 
333 preferred to genetic or other evolutionary-based algorithms, following other simulation-based 334 optimization studies of geothermal energy systems [22]. A similar procedure to that of Clarke et al. 335 [22] was used through the formulation of the PSO algorithm in MATLAB and by linking this to 336 EES. Two sets of competing objective functions were considered: (1) total specific cost $v s$. thermal 337 efficiency, and (2) total cost rate $v s$. exergy efficiency.

For each multi-objective optimization case, Pareto frontiers consisting of optimum solution points were extracted with three highlighted points on each one; Point A: denoting the maximum thermal efficiency, Point B: indicating the minimum total specific cost, and Point C: showing a balanced condition between efficiency and cost using LINMAP and TOPSIS methods. solution points from the LINMAP and TOPSIS methods. For example, when the thermal efficiency and total specific cost are considered as the objective functions, Euclidean distances can be calculated between the normalized optimal and ideal solutions as follows [46]:

where $w_{1}$ and $w_{2}$ are weighting coefficients and the normalized functions are determined from [46]:

$$
E D_{i}^{+}=\sqrt{w_{1}\left(\eta_{\mathrm{th}, i}^{\mathrm{N}}-\eta_{\mathrm{th}, \text { ideal }}^{\mathrm{N}}\right)^{2}+w_{2}\left(c_{\mathrm{P}, \text { tot }, i}^{\mathrm{N}}-c_{\mathrm{P}, \text { tot,ideal }}^{\mathrm{N}}\right)^{2}}
$$
where $w_{1}$ and $w_{2}$ are weighting

$$
\eta_{\mathrm{th}, i}^{\mathrm{N}}=\frac{\eta_{\mathrm{th}, i}}{\sqrt{\sum_{i}\left(\eta_{\mathrm{th}, i}\right)^{2}}}, c_{\mathrm{P}, \mathrm{tot}, i}^{\mathrm{N}}=\frac{c_{\mathrm{P}, \mathrm{tot}, i}}{\sqrt{\sum_{i}\left(c_{\mathrm{P}, \mathrm{tot}, i}\right)^{2}}}
$$

The weighting coefficients are set to unity when the two objective functions are equally important, or different values can be selected when one of the objective functions is more important. In this study, equal weighting coefficient values (i.e., $w_{1}=w_{2}=1$ ) have been considered. LINMAP method. In addition, non-ideal solutions indicated as $E D_{i}^{-}$were also considered for the TOPSIS method, following a similar approach [46]:

$$
E D_{i}^{-}=\sqrt{w_{1}\left(\eta_{\mathrm{th}, i}^{\mathrm{N}}-\eta_{\mathrm{th}, \text { non-ideal }}^{\mathrm{N}}\right)^{2}+w_{2}\left(c_{\mathrm{P}, \text { tot }, i}^{\mathrm{N}}-c_{\mathrm{P}, \text { tot,non-ideal }}^{\mathrm{N}}\right)^{2}}
$$

Subsequently, a relative closeness $\left(R_{C}\right)$ was evaluated, defined as:

$$
R_{C, i}=\frac{E D_{i}^{-}}{E D_{i}^{-}+E D_{i}^{+}}
$$


where the maximum value of $R_{C}$ was selected as the final optimum when using the TOPSIS method. and total cost rate were considered as the objective functions. The input parameters used to conduct MOPSO and the procedure followed in this study are presented in Fig. 3.

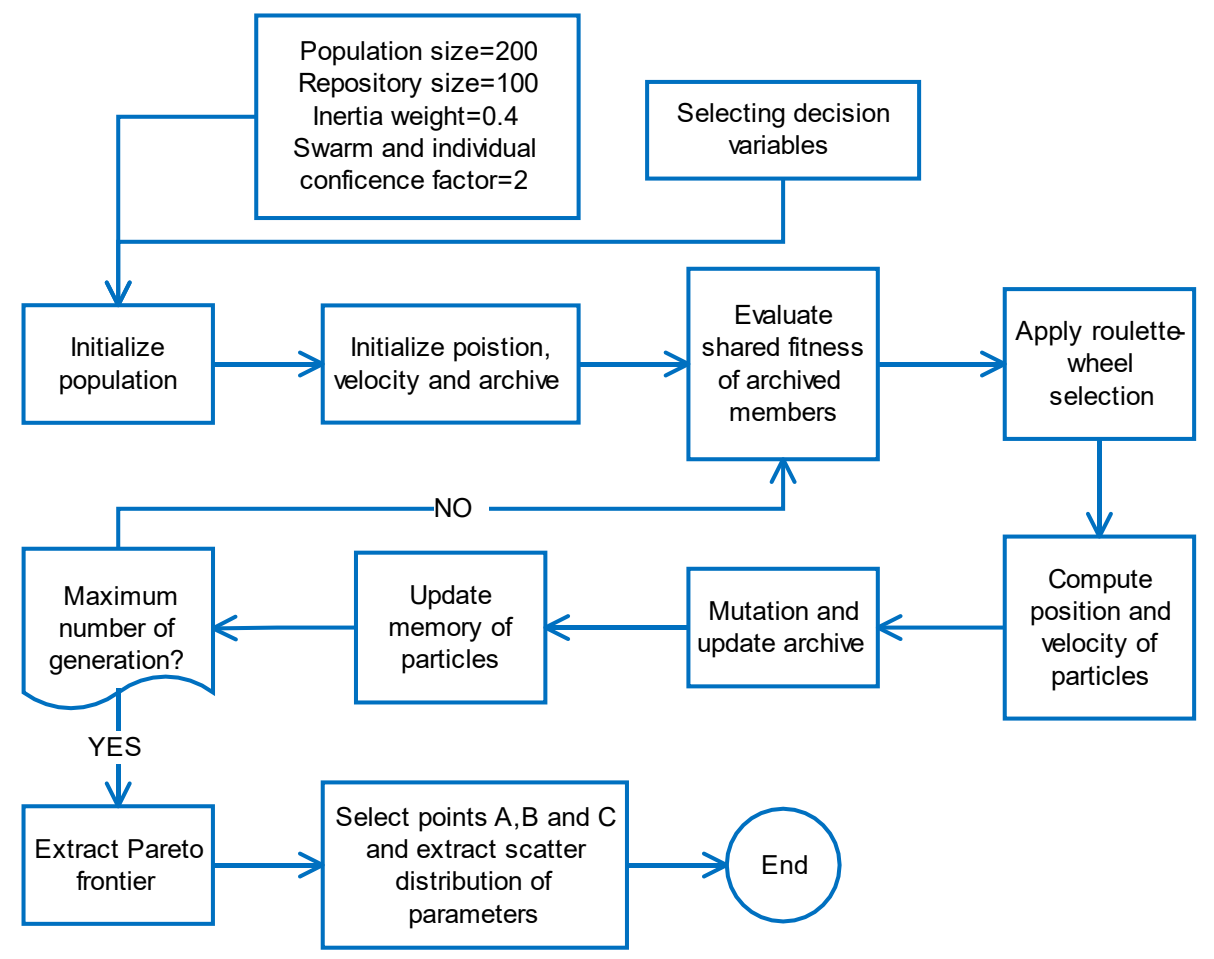

Figure 3: Input parameters used and MOPSO procedure followed in this study

\section{Results and discussion}

366 The three proposed configurations are compared in terms of energy, exergy and exergoeconomic

367 criteria to determine the strengths and weaknesses of each one. Firstly, results from a parametric

368 study are presented to assess the impact of key decision variables on system performance.

369 Subsequently, results relating to optimized systems through multi-objective optimization are

370 presented. Prior to these assessments, the system performance and cost indicators were evaluated

371 when employing different working fluids at the baseline (see Table 1). For Configuration (a), a

372 wide range of hydrocarbons with low global warming and ozone depletion potentials (GWP and

373 ODP) were considered, including Ethylbenzene, Isobutane, Isobutene, Isopentane, Isohexane, n-

374 Butane, n-Pentane, n-Hexane, n-Octane, n-Undecane, o-Xylene, Toluene, and others, e.g., 
375 Isopropanol. Further useful information on these refrigerants can be found in Ref. [47]. It was 376 concluded that Isobutane is a particularly favourable working fluid for this configuration, as it 377 results in a well-balanced condition in terms of thermal and exergy efficiencies, and total specific 378 cost, so this fluid is selected for the rest of this study (see Table 3). For Configurations (b) and (c), 379 an ammonia-water mixture and water as working fluids are used, respectively.

380 Table 3: System performance and characteristics of working fluids examined for Configuration (a)

\begin{tabular}{lcccccccc}
\hline Fluid & $\begin{array}{c}\boldsymbol{\eta}_{\text {th }} \\
(\boldsymbol{\%})\end{array}$ & $\begin{array}{c}\boldsymbol{\eta}_{\mathbf{e x}} \\
(\boldsymbol{\%})\end{array}$ & $\begin{array}{c}\boldsymbol{c} \mathbf{P}, \text { tot } \\
(\mathbf{\$} / \mathbf{G J})\end{array}$ & $\begin{array}{c}\mathbf{G W P} \\
(\mathbf{1 0 0} \mathbf{y r})\end{array}$ & $\begin{array}{c}\text { ODP } \\
(\mathbf{1 0 0} \mathbf{~ y r})\end{array}$ & $\begin{array}{c}\text { Safety } \\
\text { group }\end{array}$ & $\begin{array}{c}\boldsymbol{T}_{\text {crit }} \\
\left({ }^{\circ} \mathbf{C}\right)\end{array}$ & $\begin{array}{c}\boldsymbol{P}_{\text {crit }} \\
(\mathbf{M P a})\end{array}$ \\
\hline Isobutane & 18.5 & 56.6 & 32.6 & 3 & 0 & $\mathrm{~A} 3$ & 135 & 3.64 \\
Toluene & 18.2 & 56.9 & 33.3 & 0 & 0 & - & 319 & 4.13 \\
Isohexane & 17.7 & 56.7 & 33.9 & $3-20$ & 0 & $\mathrm{~A} 3$ & 225 & 3.04 \\
Isobutene & 18.5 & 56.8 & 33.5 & 3 & 0 & $\mathrm{~A} 3$ & 145 & 4.01 \\
Ethylbenzene & 17.7 & 57.1 & 33.1 & - & 0 & - & 344 & 3.62 \\
Isopentane & 17.2 & 57.2 & 36.9 & 11 & 0 & $\mathrm{~A} 3$ & 187 & 3.37 \\
Isopropanol & 17.0 & 57.6 & 33.6 & $3-20$ & 0 & - & 235 & 4.76 \\
n-Butane & 18.4 & 56.7 & 35.4 & $3-20$ & 0 & $\mathrm{~A} 3$ & 152 & 3.80 \\
n-Hexane & 17.9 & 56.7 & 33.6 & $3-20$ & 0 & $\mathrm{~A} 3$ & 235 & 3.06 \\
n-Octane & 16.7 & 57.1 & 33.0 & $3-20$ & 0 & A3 & 296 & 2.50 \\
n-Pentane & 17.6 & 56.9 & 35.6 & 11 & 0 & A3 & 196 & 3.36 \\
n-Undecane & 16.0 & 57.1 & 32.6 & $3-20$ & 0 & - & 366 & 1.99 \\
o-Xylene & 17.6 & 57.1 & 33.0 & $3-20$ & 0 & - & 357 & 3.74 \\
R1243zf & 15.0 & 56.7 & 32.7 & 0.82 & 0 & A2L & 106 & 3.61 \\
R1234yf & 13.4 & 56.8 & 33.2 & 4 & 0 & A2L & 94.7 & 3.38 \\
R1234ze(E) & 15.9 & 56.7 & 33.3 & $<1$ & 0 & A2L & 109 & 36.4 \\
Novec649 & 15.7 & 56.9 & 34.2 & $<1$ & 0 & - & 169 & 1.88 \\
Dimethylether & 15.3 & 57.0 & 33.2 & 1 & 0 & A3 & 127 & 5.34 \\
\hline
\end{tabular}




\subsection{Validation}

383 The results provided in Table 4 are provided as a form of verification of the absorption and ejector

384 refrigeration system models, and of the absorption power cycle model. For this, results from a

385 number of recognized numerical studies in the literature have been employed, selected where it

386 was deemed that sufficient information was provided for our purposes. Specifically, Garcia-

387 Hernando et al. [48] modelled an absorption power cycle (others, e.g., Novotny and Kolovratnik

388 [49] also reported similar results) and Lostec et al. [50] examined an absorption refrigeration cycle

389 experimentally, so our results are compared to those provided by these authors. Furthermore, an

390 experimental study on the ejector refrigeration cycle [51] was selected here for the verification of

391 this subsystem. The maximum absolute error resulting from the comparison of the present study

392 results with those reported in these publications is $1.4 \%$ for the simulation of the absorption power

393 cycle, and $5.0 \%$ and $4.5 \%$ for the absorption and ejector refrigeration systems, respectively.

394 Table 4: Verification of absorption power, absorption refrigeration and ejector refrigeration sub-

395 systems, and of the system geothermal section

\begin{tabular}{|c|c|c|c|}
\hline \multicolumn{4}{|c|}{ Absorption power cycle (steam generator temperature $=100^{\circ} \mathrm{C}$, absorber pressure $=7.4 \mathrm{kPa}$ ) } \\
\hline $\begin{array}{c}\text { Generator pressure } \\
\text { (kPa) }\end{array}$ & $\begin{array}{c}\text { Efficiency (\%) } \\
\text { (Ref. [48]) }\end{array}$ & $\begin{array}{l}\text { Efficiency (\%) } \\
\text { (Present study) }\end{array}$ & $\begin{array}{c}\text { Error } \\
(\%)\end{array}$ \\
\hline 30.0 & 7.2 & 7.3 & 1.4 \\
\hline 40.0 & 8.5 & 8.6 & 1.2 \\
\hline 50.0 & 9.3 & 9.2 & -1.1 \\
\hline 57.2 & 9.2 & 9.1 & -1.1 \\
\hline \multicolumn{4}{|c|}{ Absorption refrigeration cycle (working fluid: $\mathrm{NH}_{3}$-water, refer to $\mathrm{Ref} .[50]$ for full details of tests } \\
\hline Test number & $\begin{array}{c}\text { COP } \\
(\text { Ref. }[50])\end{array}$ & $\begin{array}{c}\text { COP } \\
\text { (Present study) }\end{array}$ & $\begin{array}{c}\text { Error } \\
(\%)\end{array}$ \\
\hline Test 1 & 0.60 & 0.62 & +3.3 \\
\hline Test 8 & 0.20 & 0.19 & +5.0 \\
\hline Test 15 & 0.11 & 0.11 & 0 \\
\hline Test 18 & 0.30 & 0.29 & -3.3 \\
\hline \multicolumn{4}{|c|}{ Ejector refrigeration cycle (condenser temperature: $303.15 \mathrm{~K}$ ) } \\
\hline $\begin{array}{c}\text { Generator } \\
\text { temperature }\left({ }^{\circ} \mathbf{C}\right)\end{array}$ & $\begin{array}{c}\text { Entrainment ratio } \\
\text { (Ref. [51]) }\end{array}$ & $\begin{array}{c}\text { Entrainment ratio } \\
\text { (Present study) }\end{array}$ & $\begin{array}{c}\text { Error } \\
(\%)\end{array}$ \\
\hline
\end{tabular}




\begin{tabular}{|c|c|c|c|}
\hline 102 & 0.10 & 0.10 & 0 \\
\hline 104 & 0.45 & 0.44 & -2.2 \\
\hline 106 & 0.66 & 0.63 & -4.5 \\
\hline 112 & 0.60 & 0.61 & +1.7 \\
\hline \multicolumn{4}{|c|}{ Real data of drilling and installing costs of deep geothermal wells } \\
\hline $\begin{array}{c}\zeta\left({ }^{\circ} \mathrm{C} / \mathrm{km}\right) / \\
\text { real depth }(\mathbf{k m})\end{array}$ & $\begin{array}{l}\text { Real investment cost (M\$) } \\
\text { (Ref. [35]) }\end{array}$ & $\begin{array}{c}\text { Estimated cost (M\$) } \\
\text { (Present study) }\end{array}$ & $\begin{array}{c}\text { Error } \\
(\%)\end{array}$ \\
\hline $48.3 / 3.29^{\mathrm{a}}$ & 20.0 & 20.2 & +1 \\
\hline $47.1 / 3.24^{\mathrm{b}}$ & 19.0 & 19.0 & 0 \\
\hline \multicolumn{4}{|c|}{ Real data of geothermal fluid temperatures } \\
\hline $\begin{array}{c}\zeta\left({ }^{\circ} \mathbf{C} / \mathbf{k m}\right) / \\
\text { real depth }(\mathbf{k m})\end{array}$ & $\begin{array}{c}\text { Measured brine production } \\
\text { temperature }\left({ }^{\circ} \mathbf{C}\right) \\
\text { (Refs. }[35,52])\end{array}$ & $\begin{array}{c}\text { Estimated brine production } \\
\text { temperature }\left({ }^{\circ} \mathbf{C}\right) \\
\text { (Present study) }\end{array}$ & $\begin{array}{c}\text { Error } \\
(\%)\end{array}$ \\
\hline $58.0 / 4.22^{\mathrm{c}}$ & 215 & 210 & -2.3 \\
\hline $31.9 / 4.26^{\mathrm{d}}$ & 115 & 117 & +1.7 \\
\hline
\end{tabular}

$396{ }^{a}$ In Landau, Germany; ${ }^{b}$ Average data of several real geothermal projects in Upper Rhine Graben,

397 Germany; ${ }^{c}$ In Cooper Basin, Australia; ${ }^{d}$ In Taufkirchen, Germany.

In order to validate the estimation of geothermal section return temperature (brine production

400 temperature) and costs, real data reported by Weinand et al. [35] and Hogarth et al. [52] concerning

401 established projects in different regions of Germany and Australia were considered. From the results

402 in Table 4, it can be concluded that predictions of the return temperature of the geothermal brine as

403 well as of the investment cost from the models in the present work are in good agreement with those

404 reported in the literature. It should be noted that investment costs may vary significantly across

405 projects, labour quota, regions, amongst others; however, results from our approach can be

406 considered reasonable midway costs. The geothermal temperature gradient $(\zeta)$, geothermal brine

407 mass flowrate and drilling depth are all considered as inputs to the models (see Appendix A for full 408 details). 


\subsection{Exergy and cost flow diagrams}

411 The three proposed geothermal system configurations are examined here from exergetic and 412 exergoeconomic perspectives. Corresponding results are presented in the Sankey diagrams in 413 Figs. 4 and 5, to show exergy and cost flows respectively.

414 According to Fig. 4, Configuration (c) is capable of extracting more exergy from the 415 geothermal brine heat-source stream as the brine leaving the system has less exergy compared 416 to that of the other two configurations. Nevertheless, the net power output of Configuration (a) 417 is the highest of all three configurations. In addition, from Fig. 5, it is observed that for a constant 418 cost rate flowing through the system from the geothermal brine stream, the cost rate associated 419 with the turbine power output takes the highest value for Configuration (a), while the 420 exergoeconomic factor of the turbine is highest for Configuration (b). The indicates that the share 421 of the cost of exergy destruction is lower than the investment cost rate of the turbine for 422 Configuration (b). All values of $f$, which indicates the fraction of the cost rate of exergy 423 destruction compared to the investment cost rate of each component, are shown in Fig. 5. 



Figure 4: Exergy flows (kW) within Configurations (a) to (c), from top to bottom 

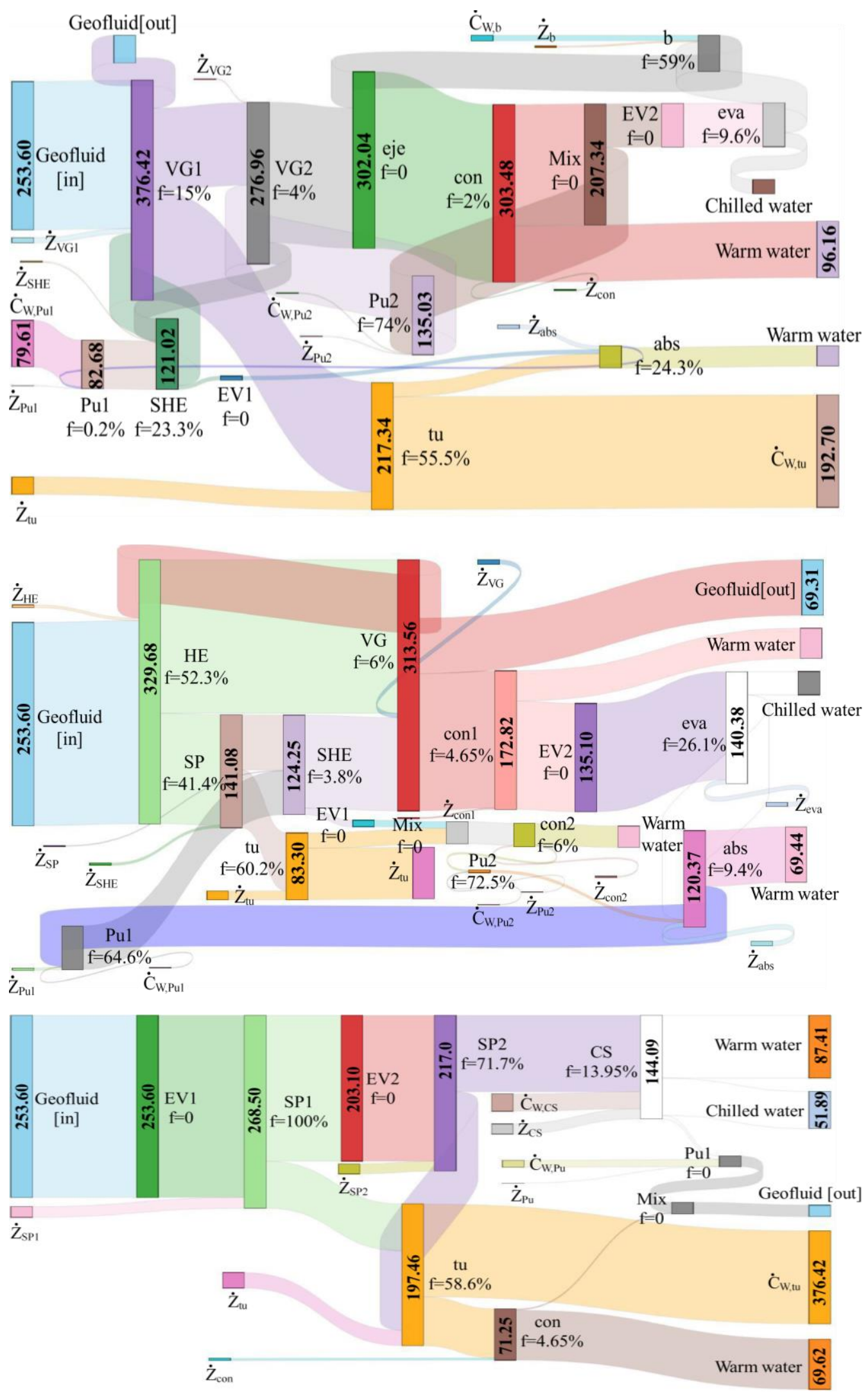

Figure 5: Cost flows $(\$ / \mathrm{h})$ within Configurations (a) to (c), from top to bottom 


\subsection{Parametric study}

433 Results are presented in this section from a sensitivity analysis performed to predict the impact of 434 important variables and parameters within reasonable variation ranges. A number of parameters 435 are selected as effective decision variables, and a reasonable range of variation is assigned in each 436 case to the selected parameters. Specific input decision variables of the studied configurations are considered to complement the parametric study.

\subsubsection{Configuration (a) specific parameters}

440 Some parameters can have a direct impact on the performance of Configuration (a), so their effects 441 should be considered. The role of the turbine inlet pressure $P_{\text {in,tu }}$ is explored in Fig. 6 over the 442 range $30 \mathrm{kPa}$ to $120 \mathrm{kPa}$, which shows significantly higher cooling capacities at higher pressures 443 due to increased working fluid flow rates through the evaporator. However, there is an optimum 444 net power output (3.3 MW) associated with an inlet pressure of $P_{\text {in,tu }}=70 \mathrm{kPa}$, at which point the 445 enthalpy drop across the turbine is maximized.

446 The exergy efficiency trend closely follows that of the power output, with a local maximum 447 exergy efficiency (59\%) achieved at a turbine inlet pressure of $80 \mathrm{kPa}$. On the other hand, the overall 448 thermal efficiency increases monotonically from $10.6 \%$ to $20.8 \%$ thanks to the significant increase 449 in the cooling capacity within the investigated range of turbine inlet pressures. In addition, at higher 450 turbine inlet pressures the total cost rate of this system increases as the purchase cost of the turbine 451 increases, while from a turbine inlet pressure of $100 \mathrm{kPa}$ upwards, the total cost rate reduces slightly. 452 Furthermore, as there is an optimum point in terms of power output, there is also a corresponding 453 minimum point for the total specific cost, since the trends of the output power and total specific cost 454 are reversed. The total cost rate does not determine the total specific cost, as the total cost changes 455 slightly within the investigation range and the specific cost is determined by the changes in power.

The mass fraction of $\mathrm{LiBr}, X_{\mathrm{LiBr}}$, in the absorption cycle is also an important parameter that should be considered during the design of the system; the effects of this parameter are also shown in 458 Fig. 6. A rich/strong fluid mixture, with a higher fraction of $\mathrm{LiBr}$, is expected to be beneficial in terms 459 of cooling and thermal efficiency since a higher mass fraction can increase the enthalpy difference in 460 the evaporator and improve the cooling capacity. However, it should be noted that when increasing 
461 the mass fraction $X_{\mathrm{LiBr}}$ from 0.2 to 0.4 , the net power output decreases by more than $50 \%$, from $4624.0 \mathrm{MW}$ to 1.8 MW, while the exergy efficiency and total cost rate follow a similar trend, i.e., decrease 463 from about $66 \%$ to $37 \%$, and $379 \$ / \mathrm{h}$ to $373 \$ / \mathrm{h}$, respectively. The reduced total cost rate arises from 464 the lower cost of the turbine, which itself relates to the reduced power rating and the requirement for 465 a smaller component. However, as the total cost rate increases and the net power output decreases, 466 the total specific cost increases significantly, in fact, doubles from 26.3 \$/GJ to 54.1 \$/GJ, at higher 467 mass fractions of $\mathrm{LiBr}$. It is noteworthy that the rates at which the total cost rate decreases and at 468 which the total specific cost (slope of the curves) increase sharply at the higher studied mass fractions.

469
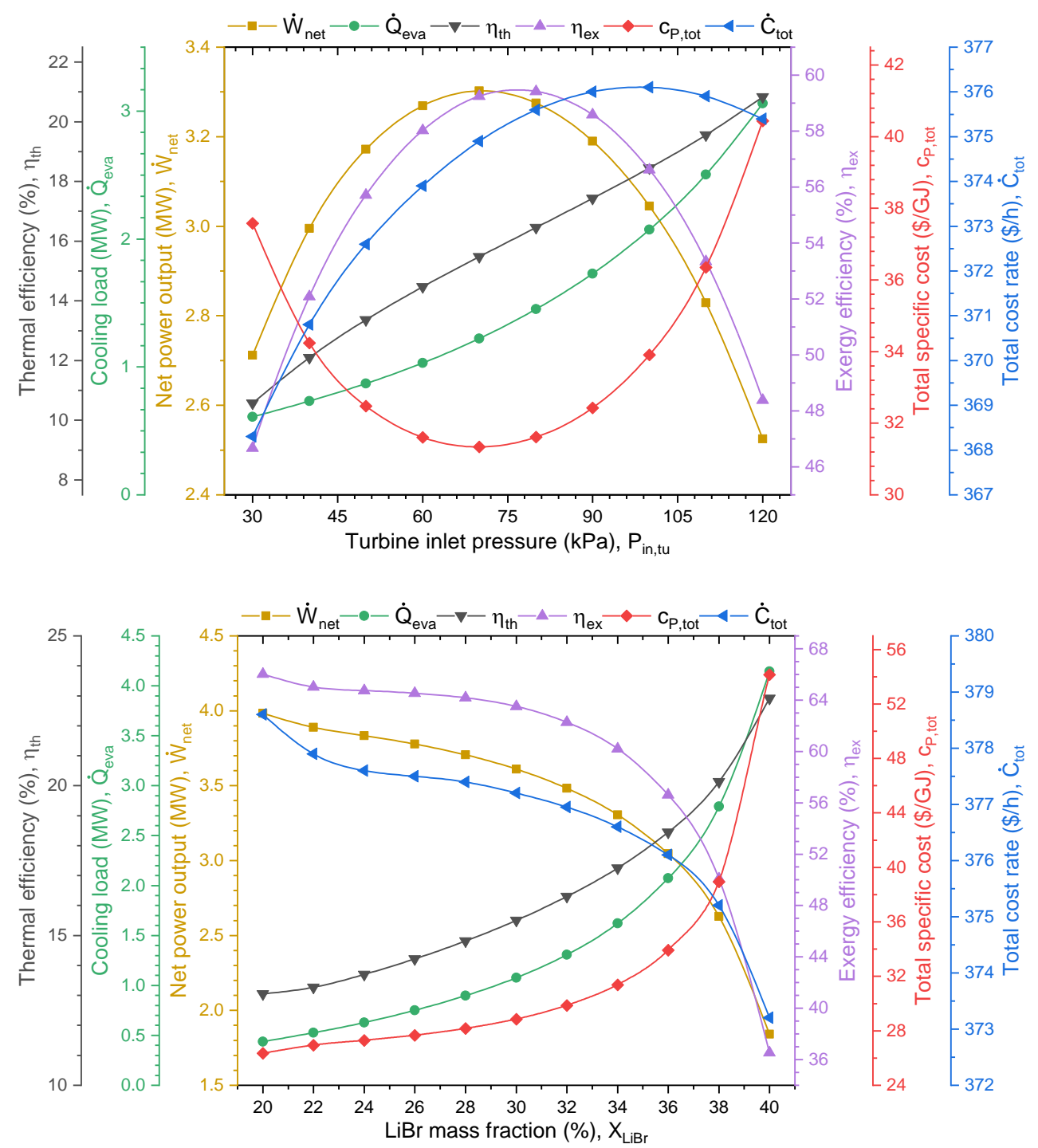

Figure 6: Effect of turbine inlet and $\mathrm{LiBr}$ mass fraction on performance of Configuration (a) 


\subsubsection{Configuration (b) specific parameters}

474 The temperature difference between Streams 1 and 2, $\Delta T_{\mathrm{HE}}$, in Configuration (b) is considered as 475 the first influential factor of interest. Results in Fig. 7 show the effect of this temperature difference 476 on key technoeconomic performance indicators, over the range $\Delta T_{\mathrm{HE}}=7-20{ }^{\circ} \mathrm{C}$. Larger temperature 477 differences enable a slightly improved cooling capacity (by $\sim 3 \%$ ), while the power output 478 reduces by about $20 \%$, from $760 \mathrm{~kW}$ to $610 \mathrm{~kW}$. This can be explained in terms of the lower 479 temperatures at the turbine inlet at higher $\Delta T_{\mathrm{HE}}$, and the consequent reduction in the enthalpy 480 drop across the turbine, which reduces the generated power output. Changes to the temperature 481 difference $\Delta T_{\mathrm{HE}}$ do not affect the exergy and thermal efficiencies; the exergy efficiency reduces 482 slightly from $19.5 \%$ to $16.4 \%$, while the overall thermal efficiency remains almost constant. The 483 reduced power output and improved cooling capacity lead to a constant thermal efficiency, while 484 a monotonically decreasing exergy efficiency can be observed at higher $\Delta T_{\mathrm{HE}}$. From an 485 exergoeconomic standpoint, there is a local optimum in terms of total cost rate $(362 \$ / \mathrm{h})$ at the 486 temperature difference of $13{ }^{\circ} \mathrm{C}$, which relates to the capital cost of the components. However, 487 the total specific cost of the system consistently increases as the temperature difference is 488 increased further, following the trend of continuous decrease in the net power output.

489 Conversely, as also shown in Fig. 7, the temperature difference between Streams 2 and $4907, \Delta T_{\text {hot,HE}}$, has a different impact on the performance of this system configuration. The results 491 indicate that a larger temperature difference, within the range $10-35^{\circ} \mathrm{C}$, leads to higher net power 492 outputs from 0.5 MW to $1.3 \mathrm{MW}$, as the enthalpy of the fluid passing through the turbine increase 493 thanks to the increased mass flow rate of Stream 9. Consequently, the exergetic efficiency of the 494 system improves from $14.4 \%$ to $28.8 \%$. By contrast, larger temperature differences considerably 495 reduce the overall thermal efficiency of the system, from $49.8 \%$ to $29.2 \%$, due to the significant 496 reduction in cooling capacity which drops by almost 50\%, from $10.7 \mathrm{MW}$ to $5.4 \mathrm{MW}$. 



$500 \quad$ Figure 7: Effect of temperature difference between Streams 1 and $2\left(\Delta T_{\mathrm{HE}}\right)$ and temperature difference between Streams 2 and $7\left(\Delta T_{\text {hot,HE}}\right)$ on performance of Configuration (b)

\subsubsection{Configuration (c) specific parameters}

504 The compressor pressure ratio $P R_{\text {com }}$ can strongly affect the performance of Configuration (c). The detailed effects of this parameter are shown in Fig. 8. Employing a higher compression pressure ratio increases the cooling capacity by a factor of more than four, from 3.7 MW to 15.3 MW within the range $1.4<P R_{\mathrm{com}}<2.8$ suggesting that this pressure ratio is particularly influential in terms of cooling capacity. At this same time, higher pressure ratios negatively affect the net power output, leading to significantly lower power outputs, which halve from 1.9 MW to 0.9 MW. This loss in 
510 power arises as a consequence of the increased enthalpy of the fluid entering the ejector, which 511 increases the cooling load of the evaporator. However, higher pressure ratios are also associated 512 with increased electrical consumption by the compressor, which reduces the net power output.

513 The effects of the compression pressure ratio $P R_{\text {com }}$ on the thermal and exergy efficiencies 514 of Configuration (c) are shown in Fig. 8. Raising the pressure ratio has a positive influence on the 515 overall thermal efficiency (which increases from $14.6 \%$ to $42 \%$ ), but a negative influence on the 516 exergy efficiency (which decreases $31.1 \%$ to $17.6 \%$ ). These results can be understood in terms of 517 the lower power generation and higher cooling capacity, respectively. In addition, an increase in the 518 pressure ratio can negatively affect the exergoeconomic metrics, as the total cost rate and total 519 specific cost both increase. Specifically, the total cost rate increases from $385 \$ / \mathrm{h}$ to $396 \$ / \mathrm{h}$ due to 520 the cost of the compressor and other components in the cooling sub-system, and the specific cost 521 increases from $54 \$ / G J$ to $97 \$ / G J$, due to the increased total cost rate and reduced power output. 522 According to Fig. 6, lower pressure ratios are preferred if exergoeconomic metrics are a priority.

523 One of the most important design parameters for Configuration (c) is the inlet pressure 524 of the second separator $P_{\mathrm{SP} 2}$, which is set by adjusting Expansion Valve 2. As shown in Fig. 8, 525 there is an optimum point, at $P_{\mathrm{SP} 2}=30-35 \mathrm{kPa}$, which maximizes performance in terms of power 526 generation and exergy efficiency. At a pressure of $30 \mathrm{kPa}$, the enthalpy drop across the turbine 527 reaches its highest value, leading to the maximum power output (1.8 MW). The cooling capacity 528 on the other hand increases monotonically from $0.6 \mathrm{MW}$ to $11.8 \mathrm{MW}$ as the pressure increases, 529 and as higher enthalpy is provided to the cooling sub-system. The increase in the cooling capacity 530 improves the thermal efficiency considerably, from $6.0 \%$ to $33.9 \%$. Furthermore, the total 531 specific cost increases slightly (from $379 \$ / \mathrm{h}$ to $392 \$ / \mathrm{h}$ ) as the pressure increases within the 532 investigated range, due to the increased capital cost of the cooling components, while the total 533 specific cost varies within the range 62-72\$/GJ, exhibiting a minimum at a pressure of $35 \mathrm{kPa}$, 534 i.e., the same as that which maximizes the exergy efficiency. 

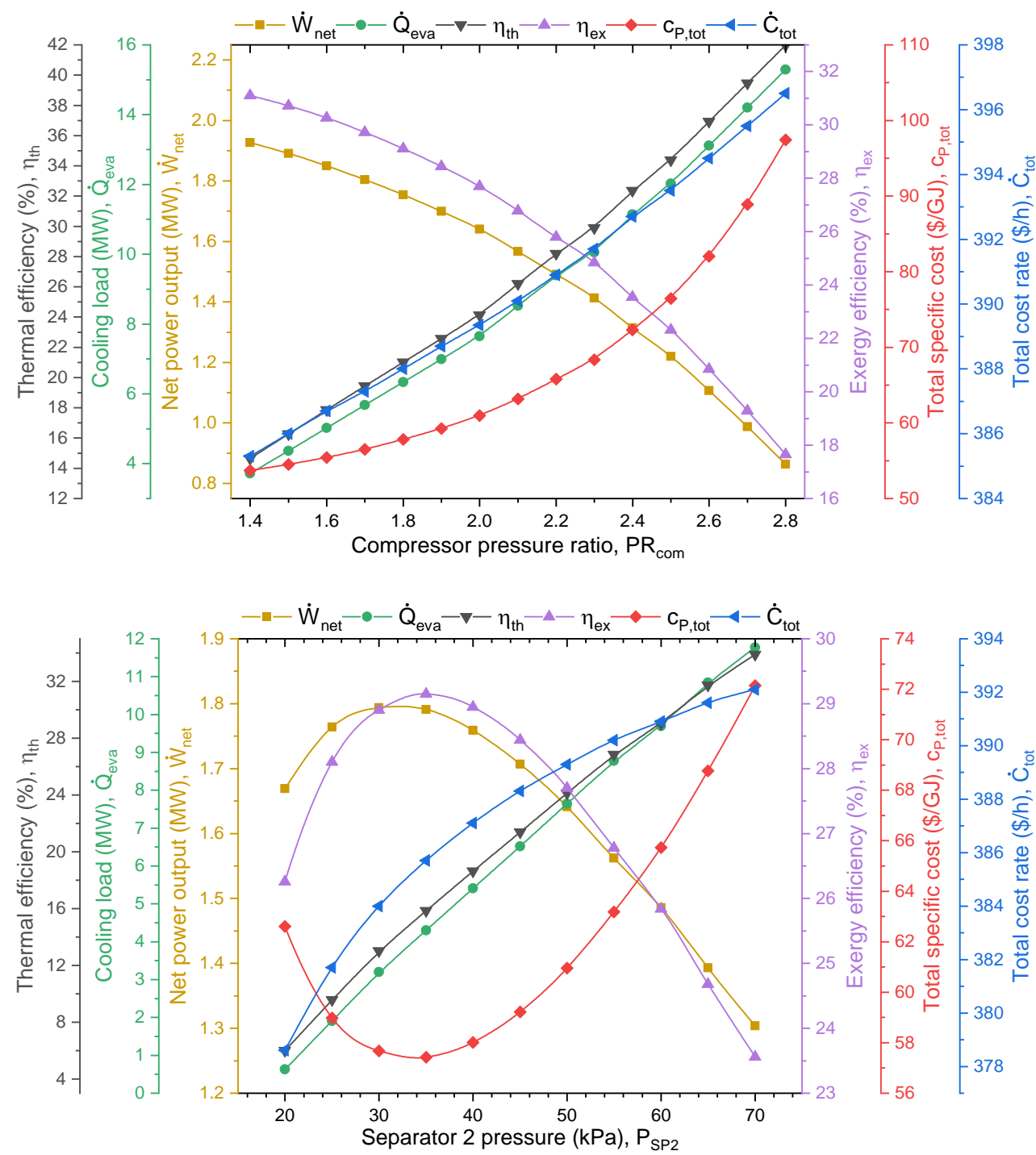

538 Figure 8: Effect of compressor pressure ratio and Separator 2 inlet pressure on performance of 539 Configuration (c)

\subsection{Multi-objective optimization}

542 In this section, multi-objective particle swarm optimization results are presented and discussed. Figure

5439 shows trade-offs between two pairs of competing objective functions: (1) thermal efficiency $v s$. total

544 specific cost, and (2) exergy efficiency $v s$. total cost rate. When considering thermal efficiency and 545 total specific cost as the competing objective functions, Pareto frontiers presenting a set of optimal 546 solution points for the proposed configurations are presented in the first (top) row, while Pareto 547 frontiers of optimal solutions gathered when exergy efficiency and total cost rate are selected as the 
548 objective functions are presented in the second (bottom) row of Fig. 9. Point A in all plots indicates 549 the maximum efficiency system design, Point B the minimum total specific cost or minimum total cost 550 rate design, and Point $\mathrm{C}$ the final optimum selected by either the LINMAP or TOPSIS method.

As shown in these plots, increasing any one of the efficiency measures in any one of the 552 system configurations always leads inevitably to rising costs. A well-balanced design is expected at 553 this point, which can be identified through such plots. The exact values of the decision variables and 554 performance indicators are also listed in Table 5 and Table 6 for all configuration designs indicated 555 by Points A, B, and C, and for each one of the different competing objective function cases.
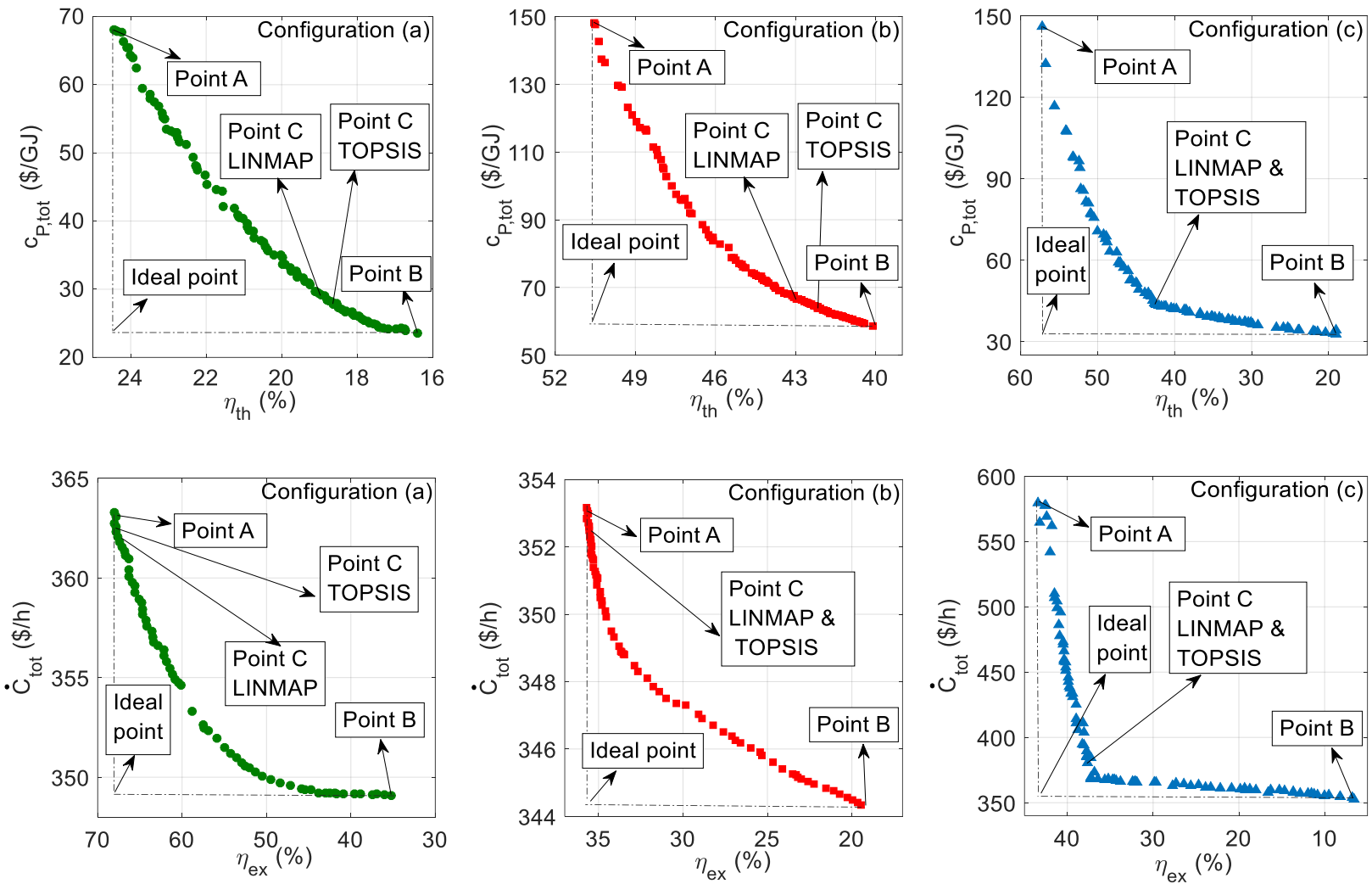

$557 \quad$ Figure 9: Pareto frontiers of optimal configurations; see Table 2 for variable range constraints 
Table 5: Multi-objective optimization results compared to the base case for different optimum points/configurations when thermal efficiency and total specific cost are the objective functions; see Table 2 for decision-variable ranges imposed through constraints

\begin{tabular}{|c|c|c|c|c|c|c|c|c|c|c|c|c|c|c|c|c|c|c|c|}
\hline ن⿺辶 & $\underbrace{\circledR \Xi}_{0}$ & $\begin{array}{l}\vec{Z} \\
\overline{4}\end{array}$ & 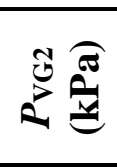 & 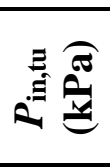 & 音 & $\hat{z}$ & $\sum^{2} 0$ & $\sum^{1}$ & 至 & 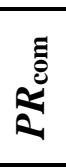 & $\overrightarrow{\tilde{\omega}}$ & 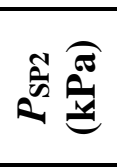 & $\overbrace{}^{\tilde{\Xi}}$ & $\underbrace{\infty}_{5}$ & $\underbrace{20}_{0}$ & . &  & $\stackrel{\Xi}{=}$ & .0 \\
\hline \multicolumn{20}{|c|}{ Base case } \\
\hline (a) & 3.8 & 10 & 1300 & 100 & 36 & 1.6 & - & - & - & - & - & - & - & 18.5 & 56.6 & 360 & 32.6 & 3040 & 2080 \\
\hline (b) & 3.8 & - & - & - & - & - & 10 & 15 & 10 & - & - & - & - & 46.2 & 18.8 & 347 & 108 & 725 & 9680 \\
\hline (c) & 3.8 & - & - & - & - & - & - & - & - & 2 & 150 & 50 & 10 & 24.1 & 27.7 & 374 & 58.6 & 1640 & 7650 \\
\hline
\end{tabular}

Point A (maximum thermal efficiency)

\begin{tabular}{|c|c|c|c|c|c|c|c|c|c|c|c|c|c|c|c|c|c|c|c|}
\hline (a) & 3.8 & 15 & 1520 & 110 & 37 & 1.6 & - & - & - & - & - & - & - & 24.4 & 30.2 & 352 & 68.1 & 1365 & 4190 \\
\hline (b) & 4.3 & - & - & - & - & - & 15 & 10 & 17 & - & - & - & - & 50.5 & 12.0 & 431 & 148 & 560 & 14430 \\
\hline (c) & 3.8 & - & - & - & - & - & - & - & - & 2.8 & 170 & 70 & 8 & 57.2 & 11.6 & 387 & 145 & 360 & 21760 \\
\hline
\end{tabular}

Point B (minimum total specific cost)

\begin{tabular}{|c|c|c|c|c|c|c|c|c|c|c|c|c|c|c|c|c|c|c|c|}
\hline (a) & 5.0 & 9 & 1200 & 110 & 37 & 1.6 & - & - & - & - & - & - & - & 16.6 & 61.3 & 576 & 23.6 & 6747 & 1555 \\
\hline (b) & 5.0 & - & - & - & - & - & 15 & 35 & 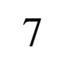 & - & - & - & - & 40.1 & 27.0 & 561 & 58.5 & 2430 & 13500 \\
\hline (c) & 5.0 & - & - & - & - & - & - & - & - & 1.4 & 240 & 68 & 8 & 19.1 & 43.0 & 582 & 32.8 & 4840 & 5720 \\
\hline
\end{tabular}

Point C (well-balanced condition, LINMAP)

\begin{tabular}{|c|c|c|c|c|c|c|c|c|c|c|c|c|c|c|c|c|c|c|c|}
\hline (a) & 4.2 & 15 & 1540 & 110 & 37 & 1.6 & - & - & - & - & - & - & - & 19.1 & 57.6 & 436 & 29.7 & 4040 & 2330 \\
\hline (b) & 5.0 & - & - & - & - & - & 15 & 28 & . & - & - & - & . & 43.0 & 23.6 & 558 & 66.9 & 2060 & 14910 \\
\hline (c) & 5.0 & - & - & - & - & - & - & - & - & 2.8 & 250 & 70 & 8 & 42.4 & 33.1 & 596 & 43.5 & 3450 & 20060 \\
\hline
\end{tabular}

Point C (well-balanced condition, TOPSIS)

\begin{tabular}{|c|c|c|c|c|c|c|c|c|c|c|c|c|c|c|c|c|c|c|c|}
\hline (a) & 4.3 & 9 & 1600 & 110 & 37 & 1.6 & - & - & - & - & - & - & - & 18.5 & 61.2 & 441 & 27.6 & 4400 & 2000 \\
\hline (b) & 5.0 & - & - & - & - & - & 15 & 30 & 7 & - & - & - & - & 42.2 & 24.7 & 559 & 64.0 & 2170 & 14510 \\
\hline (c) & 5.0 & - & - & - & - & - & - & - & - & 2.8 & 250 & 70 & 8 & 42.4 & 33.1 & 596 & 43.5 & 3450 & 20060 \\
\hline
\end{tabular}


Table 6: Multi-objective optimization results compared to the base case for different optimum points/configurations when exergy efficiency and total cost rate are the objective functions; see Table 2 for decision-variable ranges imposed through constraints

\begin{tabular}{|c|c|c|c|c|c|c|c|c|c|c|c|c|c|c|c|c|c|c|c|}
\hline نَّ & 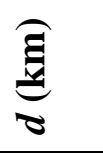 & $\xi_{4}^{j} 0$ & 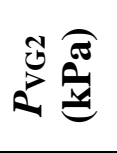 & 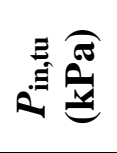 & $\stackrel{8}{8}$ & $\hat{z}$ & 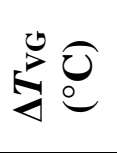 & $\sum^{ \pm}$ & 哇 & 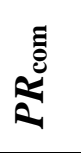 & $\widehat{\hat{\omega}} \widehat{\overparen{\theta}}$ & $\tilde{\hat{\omega}} \widehat{\overparen{E}}$ & $\overbrace{}^{\tilde{\bar{z}}}$ & $\underbrace{20}_{\equiv}$ & 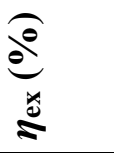 & . & 总 &  & (2) \\
\hline \multicolumn{20}{|c|}{ Base case } \\
\hline (a) & 3.8 & 10 & 1300 & 100 & 36 & 1.6 & - & - & - & - & - & - & - & 18.5 & 56.6 & 360 & 32.6 & 3040 & 2080 \\
\hline (b) & 3.8 & - & - & - & - & - & 10 & 15 & 10 & - & - & - & - & 46.2 & 18.8 & 347 & 108 & 725 & 9680 \\
\hline (c) & 3.8 & - & - & - & - & - & - & - & - & 2 & 150 & 50 & 10 & 24.1 & 27.7 & 374 & 58.6 & 1640 & 7650 \\
\hline
\end{tabular}

Point A (maximum exergy efficiency)

\begin{tabular}{lccccccccccccccccccc} 
(a) & 3.8 & 10.5 & 1217 & 109 & 20 & 1.2 & - & - & - & - & - & - & - & 12.7 & 67.8 & 363 & 24.6 & 4090 & 223 \\
(b) & 3.8 & - & - & - & - & - & 14 & 35 & 7 & - & - & - & - & 29.2 & 30.6 & 353 & 67.5 & 1362 & 5240 \\
(c) & 5.0 & - & - & - & - & - & - & - & - & 1.4 & 203 & 49 & 8 & 14.8 & 43.4 & 580 & 32.2 & 4950 & 3220 \\
\hline
\end{tabular}

Point B (minimum total cost rate)

\begin{tabular}{lccccccccccccccccccc} 
(a) & 3.8 & 15 & 1600 & 110 & 37 & 1.25 & - & - & - & - & - & - & - & 17.4 & 35.1 & 349 & 59.9 & 1580 & 2210 \\
(b) & 3.8 & - & - & - & - & - & 15 & 10 & 12 & - & - & - & - & 50.1 & 14.2 & 344 & 143 & 483 & 10800 \\
(c) & 3.8 & - & - & - & - & - & - & - & - & 1.45 & 300 & 30 & 15 & 3.3 & 6.6 & 353 & 233 & 405 & 853 \\
\hline
\end{tabular}

Point C (well-balanced condition, LINMAP)

\begin{tabular}{|c|c|c|c|c|c|c|c|c|c|c|c|c|c|c|c|c|c|c|c|}
\hline (a) & 3.8 & 12.8 & 1230 & 110 & 20 & 1.42 & - & - & - & - & - & - & - & 13.0 & 67.3 & 362 & 24.9 & 4040 & 342 \\
\hline (b) & 3.8 & - & - & - & - & - & 12.6 & 35 & 7 & - & - & - & - & 29.1 & 30.5 & 353 & 67.5 & 1360 & 5230 \\
\hline (c) & 3.9 & - & - & - & - & - & - & - & - & 1.48 & 80 & 34 & 8 & 10.5 & 37.3 & 384 & 42.7 & 2470 & 1710 \\
\hline
\end{tabular}

Point C (well-balanced condition, TOPSIS)

\begin{tabular}{|c|c|c|c|c|c|c|c|c|c|c|c|c|c|c|c|c|c|c|c|}
\hline (a) & 3.8 & 12.2 & 1210 & 110 & 20 & 1.36 & - & - & - & - & - & - & - & 12.9 & 67.7 & 362 & 24.8 & 4060 & 304 \\
\hline (b) & 3.8 & - & - & - & - & - & 12.6 & 35 & 7 & - & - & - & - & 29.1 & 30.5 & 353 & 67.5 & 1360 & 5230 \\
\hline (c) & 3.9 & - & - & - & - & - & - & - & - & 1.48 & 80 & 34 & 8 & 10.5 & 37.3 & 384 & 42.7 & 2470 & 1710 \\
\hline
\end{tabular}


556 A comparison of the performance of the three systems is shown in Fig. 10, with respect to different objectives. All system designs correspond to the final optimal point (Point C, LINMAP), which is a balanced condition between thermal efficiency and total specific cost (first (top) row), and exergy efficiency and total cost rate (second (bottom) row). The systems are also compared to conventional ORC [2] and Kalina cycle systems [53], that are considered appropriate benchmarks. The final optimal designs that balance thermal efficiency and specific cost (top row) suggest a preference for deeper wells (higher source temperatures) than those that balance exergy efficiency and total cost (bottom row), so an ORC system with isobutane as the working fluid is considered a suitable choice for comparison with the former systems, and a Kalina cycle system with an $\mathrm{NH}_{3}$ mass fraction of 0.9 for higher exergy efficiency a more suitable choice for comparison with the latter. geothermal well depth from $4.2 \mathrm{~km}$ to $5.0 \mathrm{~km}$ for Configuration (a) leads to only small changes in the results (except for total cost rate), so comparisons of this system configuration with conventional ORC systems can be considered reliable even if the depth of the geothermal well is different. For a depth of $d=5.0 \mathrm{~km}$, the total cost rate of Configuration (a) increases by $30 \%$ and reaches $570 \$ / \mathrm{h}$, which is still lower than that needed for a conventional geothermal ORC system.

From Fig. 10, it can be seen that Configuration (a) has the highest power output and exergy efficiency, but the lowest cooling capacity and overall thermal efficiency of all systems; it is also the most cost efficient as it has the lowest total specific cost. On the other hand, Configurations (b) and (c) can generate the most cooling with the latter also generating reasonable power output, and at a reasonable total specific cost. Configuration (b) has the highest thermal efficiency but also total specific cost, by far, of all systems, which is an important disadvantage of this system.

It is now important to compare the proposed systems to conventional geothermal systems. From the results in the top row of Fig. 10, which are the final optimal solutions determined by the LINMAP method when thermal efficiency and total specific cost are the competing objective functions, it can be seen that Configuration (a) outperforms an optimized conventional ORC system in almost every aspect except power output and specific cost, which are similar to those of the ORC system that, however, is optimized for power generation alone without a cooling capacity. All other

584 configurations have higher thermal efficiencies than the conventional ORC system, but also lower 585 power outputs, exergy efficiencies and total specific costs. 
As mentioned earlier, the results in the bottom row of Fig. 10, which are the final optimal solutions determined by the LINMAP method when exergy efficiency and total cost rate are the competing objective functions, are selected for the comparison with Kalina geothermal systems. The final optimal solutions suggest a preference for shallower geothermal wells in this case (unlike the top row in the same figure), so a conventional Kalina geothermal system appears as a reasonable choice for comparison purposes at $d=3.8 \mathrm{~km}$. From these results, Configuration (a) is shown to also outperform Kalina cycle systems except for power output and specific cost, which are similar to those of the Kalina system that, however, has zero cooling capacity.
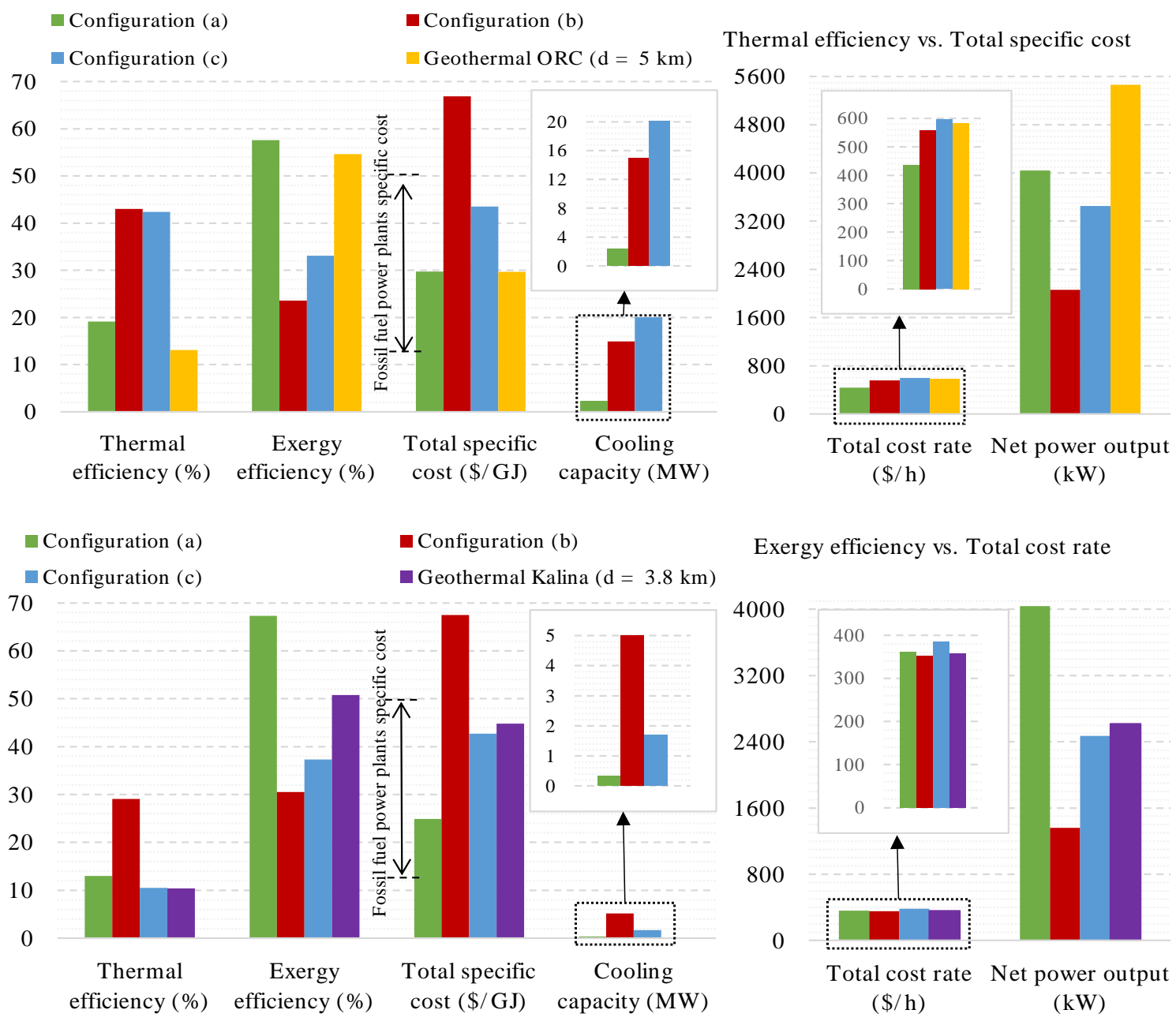

Figure 10: Comparisons of Point C (LINMAP) system design performance for Configurations (a) to (c), also including conventional ORC and Kalina-cycle systems. Top - optimal thermal efficiency and total 
specific cost, with Configuration (a): $d=4.2 \mathrm{~km}$; and Configurations (b) and (c): $d=5.0 \mathrm{~km}$. Bottom optimal exergy efficiency and total cost rate, with Configurations (a), (b) and (c): $d=3.8-3.9 \mathrm{~km}$.

To summarize, selecting a suitable system is based on the perspective of the decisionmaker(s); if maximum exergetic efficiency/power output and minimal total specific cost are the highest priority, Configuration (a) would be the preferred system. However, if the cooling capacity is a priority along with satisfactory power output, Configuration (c) is a suitable solution. On the other hand, if overall (power + cooling) thermal efficiency is the highest priority, Configuration (b) is a favourable option. The total specific cost of Configurations (a) and (c) is comparable to fossil fuel power plans, which is one of the great advantages of these configurations. The total specific cost of Configuration (b) is $35 \%$ higher than the highest specific cost of fossil fuel power plants.

In a final step, the effects of the evaporator temperature and the depth of the geothermal well on the performance of the systems are investigated, when all other decision variables are fixed to those of the final optimum point selected by the LINMAP method. Figure 11, which focuses on system designs optimized for maximum thermal efficiency and minimum total specific cost (see Table 5, Point C), shows that the exergy efficiency of Configuration (a) is higher than those of the other systems regardless of the evaporator temperature and depth of the geothermal well. However, the exergy efficiency of Configuration (c) can become higher when a deeper geothermal well is considered; however, a lower efficiency is concluded for shallower wells. Furthermore, the overall thermal efficiency of Configuration (c) varies significantly (more than the other configurations) within the explored range of parameters. The highest thermal efficiency is obtained for higher evaporator temperatures and shallower geothermal wells, while lower evaporator temperatures and/or deeper wells can reduce the thermal efficiency of this system configuration below that corresponding to Configuration (b). Evaporator temperatures above $7{ }^{\circ} \mathrm{C}$ are not applicable to Configuration (c), which is a significant drawback.

The total cost rates of all configurations are comparable and vary in a similar manner with respect to the two independent parameters (evaporator temperature and well depth). Specifically, the total cost rates are generally insensitive to the evaporator temperature and depend strongly on the well depth. The total specific cost of Configuration (c) is very high for higher evaporator temperatures and shallower geothermal wells. Configuration (b), however, shows a near-constant specific cost, while the specific cost of Configuration (a) reduces with increasing the geothermal 
629 well depth yet remains the lowest of all systems. The explanations that underpin these reported 630 observations and trends are similar to those provided in the parametric study section.

Finally, system designs optimized for maximum exergy efficiency and minimum total specific cost are presented (Table 6, Point C). Similar observations to those already reported in the

633 parametric analysis (not shown) apply to the optimized systems, wherein Configuration (a) has the

634 highest exergy efficiency and total specific cost, and Configuration (b) the highest thermal 635 efficiency. Both efficiencies, along with the specific cost, do not show strong variations within the 636 explored parameter space. As before, the total cost rates of all configurations are comparable and exhibit the largest variation, but with almost identical trends in response to changes in the 638 evaporator temperature and well depth. As mentioned above, these results align closely with observations discussed (and the associated explanations) in the parametric study section.

643 Figure 11: Effects of evaporator temperature and borehole depth of geothermal well on 644 performance indicators of proposed systems based on final optimal designs from LINMAP 645 (thermal efficiency and total specific cost are objective functions)

\subsection{Alternative thermodynamic performance indicators}

647 The definitions of thermal and exergy efficiencies that have been used thus far, characterize how 648 effectively the systems perform from a thermodynamic (first- and second-law in Eqs. (3) and (5), 649 respectively) perspective relative to the fractional energy/exergy taken from the geothermal heat 650 source. Alternative thermodynamic performance indicators (in Eqs. (4) and (6), respectively) can 651 be defined relative to the total (maximum) energy/exergy available in the heat source. In this 652 section, the results obtained for these alternative efficiency definitions are compared.

A direct comparison of the efficiency measures for optimal designs of all proposed systems at Point C (LINMAP) is presented in Fig. 12. The first set of definitions is associated with higher efficiency values, as expected, and the difference between the two thermal efficiency definitions is larger than the difference between corresponding exergy efficiency definitions. Generally, the trends of all efficiency pairs are similar, however, there are a few interesting differences of note.

With respect to the thermal efficiency, firstly, the efficiency of Configuration (a) decreases monotonically with borehole depth when considering the definition that has been used so far (Eq. (3)), but shows a clear minimum at $3.9 \mathrm{~km}$ and increases for deeper wells when considering the alternative definition (Eq. (5)). This has important implications as it leads to different conclusions concerning the optimal depth with respect to thermal efficiency for this system configuration; shallow for Eq. (3) but deep for Eq. (5). Secondly, for very deep wells Configuration (b) can 664 become more efficient than Configuration (c) when considering the definition in Eq. (3), but when considering the alternative definition in Eq. (5), Configuration (b) never approaches that of Configuration (c), even at the extreme depth explored in this work of $5 \mathrm{~km}$.

We also observe, with respect to the exergy efficiency, that the efficiency of 668 Configuration (a) exhibits a maximum at a well depth of $4.7 \mathrm{~km}$ from the perspective of the 669 definition in Eq. (3), but increases monotonically with depth when considering the alternative 670 definition. This, again, is important as it suggests that the optimal depth with respect to exergy 671 efficiency for this system configuration is not at an intermediate but at a much deeper well depth. 
Overall, decision-makers can select any one of the two established definitions, both of 673 which reveal something subtly different about the thermodynamic performance of these systems, 674 while considering the differences between these definitions. The first definition considers the 675 efficiency of the system while paying attention to the variable heat input to the system (by 676 accounting for the varying enthalpy and exergy of the geofluid stream leaving the system). The second definition, on the other hand, evaluates the efficiency of the system while considering only the enthalpy and exergy delivered to the system with the inlet geofluid stream, effectively considering that geofluid stream leaving the system has a 'lost' potential.
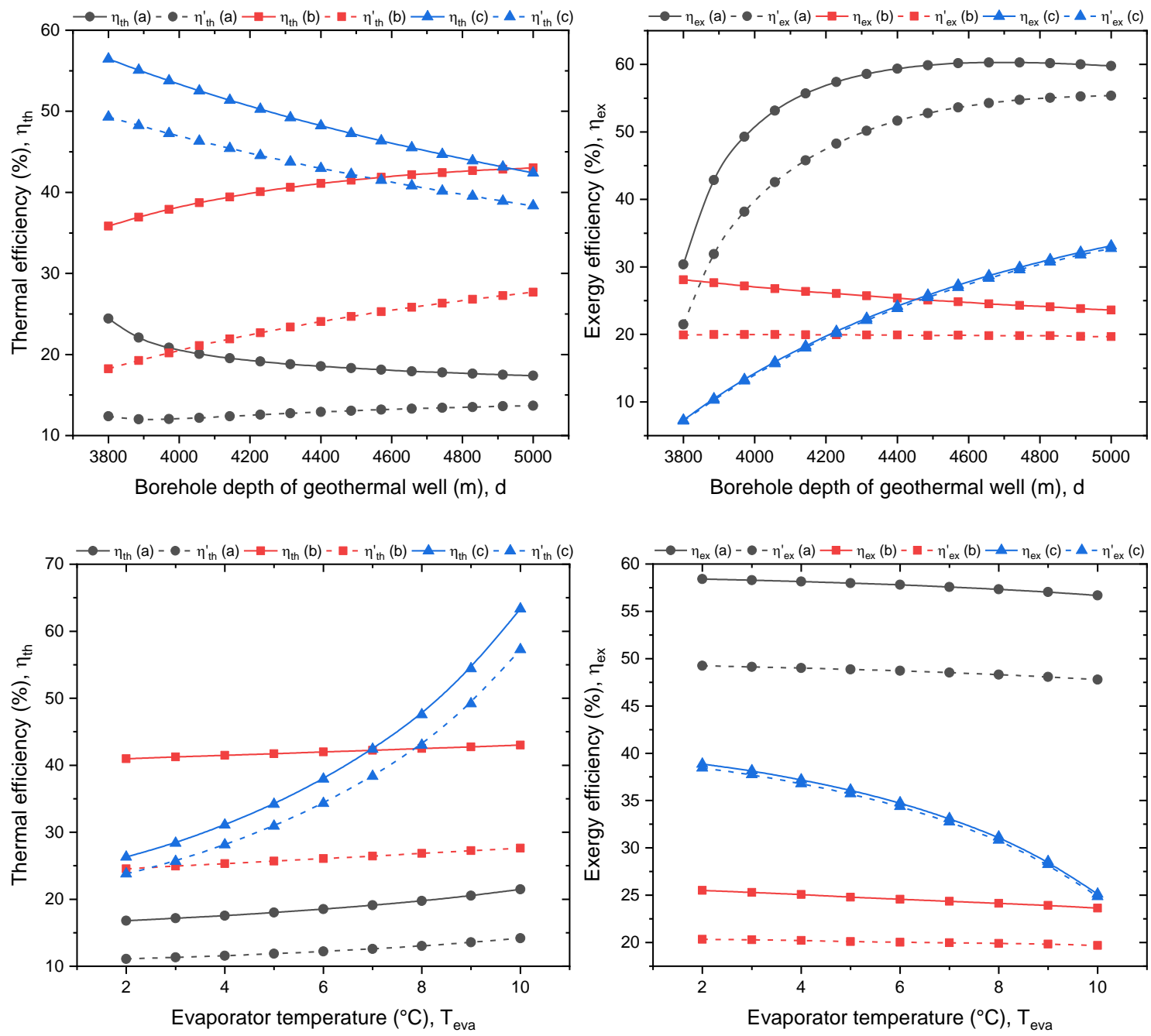

Figure 12: Comparison of first/second law efficiency definitions for proposed configurations 
686 Fig. 13, in which the alternative definitions for the thermal and exergy efficiencies are used, in conjunction with the total specific cost and total cost rate, respectively, are considered as objective functions. As can be seen, the overall trends of the optimal solutions for Configurations (b) and (c) are similar to those of the Pareto frontiers of optimal solutions from the perspective of the earlier thermal efficient definitions, shown in Fig. 9. However, the efficiency and cost ranges are different compared to those shown in Fig. 9, and the Pareto optimal solutions have different shapes and trends when different expressions of efficiency are considered. As mentioned earlier, this is important to consider when comparing the various options.

694
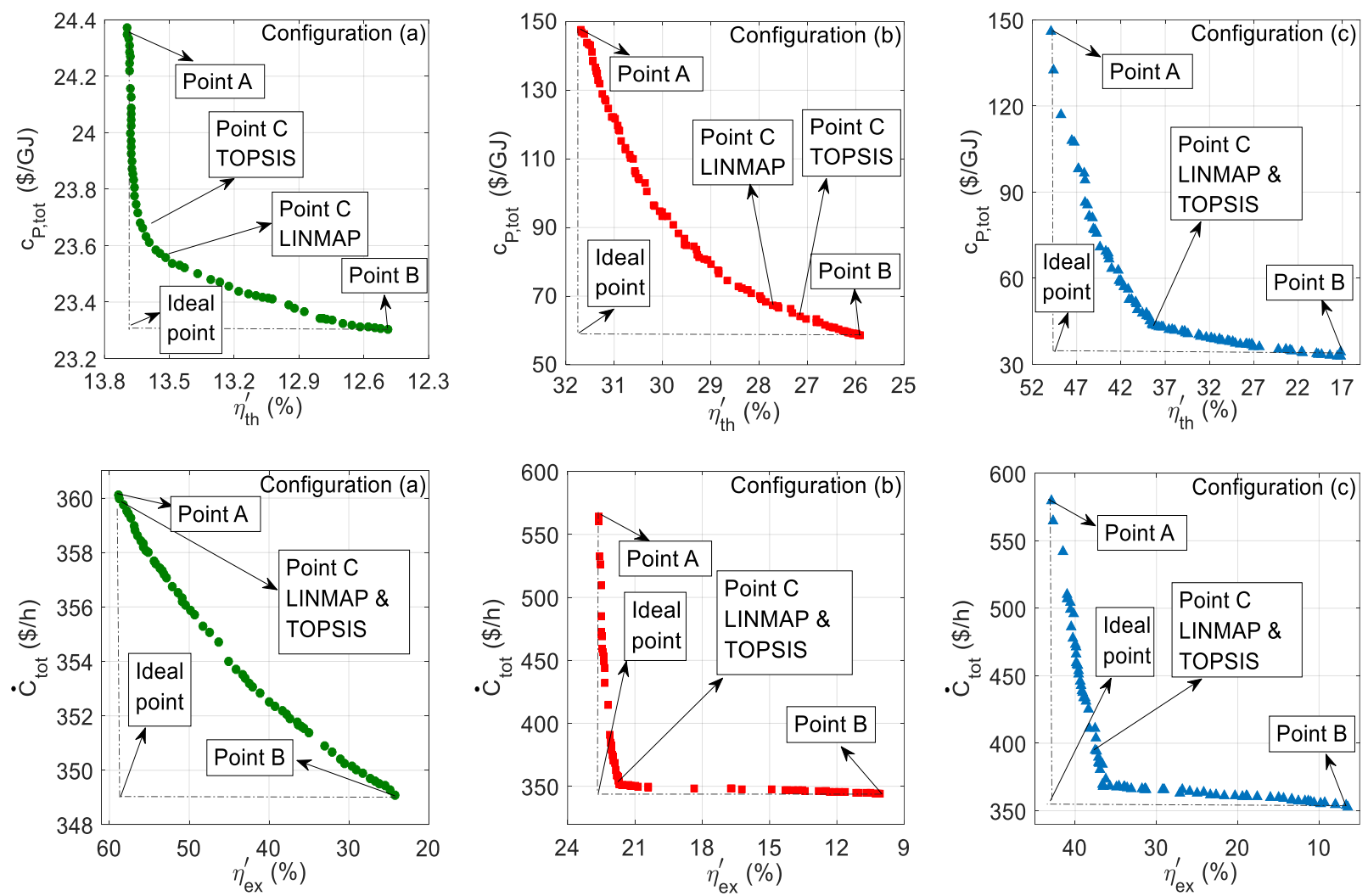

695

Figure 13: Pareto frontiers of optimal solution points when alternative definitions of thermal and exergy efficiencies are considered as the objective functions 


\section{Conclusions}

699 In this study, three novel geothermal combined cooling and power (CCP) systems were proposed.

700 The first system (Configuration (a)) comprises an absorption power cycle and an ejector 701 refrigeration cycle, the second (Configuration (b)) a modified Kalina power cycle along with an 702 absorption refrigeration cycle, and the third (Configuration (c)) a double-flash power cycle and 703 ejector refrigeration cycle, in all cases for power generation and cooling, respectively.

The three aforementioned systems were firstly compared comprehensively from both thermodynamic and economic perspectives using parametric and multi-objective particle swarm optimization. The aim of the parametric study was to understand and evaluate the effects of the most influential parameters on the systems' performance. The results revealed that Configuration (c) is particularly sensitive to the evaporator temperature, such that at the high end of investigated temperatures (i.e., 9-10 ${ }^{\circ} \mathrm{C}$ ) this system attains a cooling capacity that is even higher than that of Configuration (b), which otherwise has the best cooling performance.

The main findings from the multi-objective optimization study when the overall thermal efficiency and total specific cost are considered as competing objective functions, were:

- Deeper geothermal wells are best suited to optimal Configurations (b) and (c). When considering alternative efficiency definitions relative to the geothermal resource, the optimal depth for Configuration (a) also shifts to deeper wells.

- Overall, the final optimal design of Configuration (a) has the highest power output and exergy efficiency, but the lowest total cost rate and total specific cost. Configuration (b) has the highest thermal efficiency, while having an intermediate cooling capacity. Configuration (c) provides the most cooling, along with reasonable power output, exergy efficiency and total specific cost.

- The final optimal designs of Configurations (a) to (c) selected by the LINMAP method have thermal efficiencies of $19.1 \%, 43.0 \%$, and $42.4 \%$, respectively, exergy efficiencies of $57.6 \%, 23.6 \%$, and $33.1 \%$, total cost rate values of $436 \$ / \mathrm{h}, 558 \$ / \mathrm{h}$, and $596 \$ / \mathrm{h}$, and total specific costs of $29.7 \$ / G J, 66.9 \$ / G J, 43.5 \$ / G J$, for well depths of $4.2 \mathrm{~km}$ for Configuration (a), and $5.0 \mathrm{~km}$ for other two configurations. 
- Compared to a conventional geothermal ORC system, Configuration (a) has both higher thermal and exergy efficiencies, a lower total cost rate, and similar power output and specific cost, while also having the potential to deliver limited cooling.

Finally, the main findings when exergy efficiency and total cost are the objective functions, were:

- Shallower geothermal wells are suitable for all configurations $(d=3.8 \mathrm{~km})$.

- Overall, the final optimal design of Configuration (a) has the highest power output and exergy efficiency, the lowest total specific cost, and intermediate thermal efficiency and total cost rate, relative to the other systems. Configuration (b) has the highest cooling capacity, and thermal efficiency. Configuration(c) delivers intermediate power and cooling outputs, while having moderate exergy efficiency and total specific cost.

- The final optimal designs of Configurations (a) to (c) selected by the LINMAP method have thermal efficiencies of $13.0 \%, 29.1 \%$, and $10.5 \%$, respectively, exergy efficiencies of $67.3 \%, 30.5 \%$, and $37.3 \%$, total cost rate values of $362 \$ / \mathrm{h}, 353 \$ / \mathrm{h}$, and $384 \$ / \mathrm{h}$, and total specific costs of $24.9 \$ / G J, 67.5 \$ / G J, 42.7 \$ / G J$.

- Compared to conventional geothermal Kalina cycle systems, Configuration (a) has a higher exergy efficiency, but a slightly lower thermal efficiency, and a comparable power output, total cost rate and specific cost; the Kalina system, however, has zero cooling capacity.

In future work, different geothermal temperature gradients can also be considered for different regions which have not been considered in this study. In addition, optimal designs and system performance with integrated component performance modelling [54] as well operational modelling in the presence of heat-source (or sink) intermittency while accounting for changing component performance are important in making predictions close to expectations in practice [55]. 


\section{References}

749 [1] Song J, Loo P, Teo J, Markides CN. Thermo-Economic Optimization of Organic Rankine

750

751

752

753

754

755

756

757

758

759

760

761

762

763

764

765

766

767

768

769

770

771

772

773

774

775

776

777

778

779

780

781

782

783

784

785

786

787

788

789

Cycle (ORC) Systems for Geothermal Power Generation: A Comparative Study of System Configurations. Front Energy Res 2020;8:1-14. https://doi.org/10.3389/fenrg.2020.00006.

[2] Zare V. A comparative exergoeconomic analysis of different ORC configurations for binary geothermal power plants 2015;105:127-38 https://doi.org/10.1016/j.enconman.2015.07.073.

[3] Altun AF, Kilic M. Thermodynamic performance evaluation of a geothermal ORC power plant. Renew Energy 2020;148:261-74. https://doi.org/10.1016/j.renene.2019.12.034.

[4] Yari M. Exergetic analysis of various types of geothermal power plants. Renew Energy 2010;35:112-21. https://doi.org/10.1016/j.renene.2009.07.023.

[5] Fiaschi D, Manfrida G, Rogai E, Talluri L. Exergoeconomic analysis and comparison between ORC and Kalina cycles to exploit low and medium-high temperature heat from two different geothermal sites. Energy Convers Manag 2017;154:503-16. https://doi.org/10.1016/j.enconman.2017.11.034.

[6] Shokati N, Ranjbar F, Yari M. A comparative analysis of rankine and absorption power cycles from exergoeconomic viewpoint. Energy Convers Manag 2014;88:657-68. https://doi.org/10.1016/j.enconman.2014.09.015.

[7] Van Erdeweghe S, Van Bael J, Laenen B, D'haeseleer W. Optimal combined heat-andpower plant for a low-temperature geothermal source. Energy 2018. https://doi.org/10.1016/j.energy.2018.01.136.

[8] Zare V. A comparative thermodynamic analysis of two tri-generation systems utilizing lowgrade geothermal energy. Energy Convers Manag 2016;118:264-74. https://doi.org/10.1016/j.enconman.2016.04.011.

[9] Cao L, Wang J, Wang H, Zhao P, Dai Y. Thermodynamic analysis of a Kalina-based combined cooling and power cycle driven by low-grade heat source. Appl Therm Eng 2017;111:8-19. https://doi.org/10.1016/j.applthermaleng.2016.09.088.

[10] Zhao Y, Wang J, Cao L, Wang Y. Comprehensive analysis and parametric optimization of a CCP (combined cooling and power) system driven by geothermal source. Energy 2016;97:470-87. https://doi.org/10.1016/j.energy.2016.01.003.

[11] Abdolalipouradl M, Khalilarya S, Jafarmadar S. Exergoeconomic analysis of a novel integrated transcritical CO2 and Kalina 11 cycles from Sabalan geothermal power plant. Energy Convers Manag 2019;195:420-35. https://doi.org/10.1016/j.enconman.2019.05.027.

[12] Ambriz-Díaz VM, Rubio-Maya C, Ruiz-Casanova E, Martínez-Patiño J, Pastor-Martínez E. Advanced exergy and exergoeconomic analysis for a polygeneration plant operating in geothermal cascade. Energy Convers Manag 2020;203. https://doi.org/10.1016/j.enconman.2019.112227.

[13] Liu X, Wei M, Yang L, Wang X. Thermo-economic analysis and optimization selection of ORC system configurations for low temperature binary-cycle geothermal plant. Appl Therm Eng 2017;125:153-64. https://doi.org/10.1016/j.applthermaleng.2017.07.016.

[14] Cao L, Lou J, Wang J, Dai Y. Exergy analysis and optimization of a combined cooling and 
power system driven by geothermal energy for ice-making and hydrogen production. Energy Convers https://doi.org/10.1016/j.enconman.2018.08.067.

[15] Willems CJL, M. Nick H. Towards optimisation of geothermal heat recovery: An example from the West Netherlands Basin. Appl Energy 2019;247:582-93. https://doi.org/10.1016/j.apenergy.2019.04.083.

[16] Oyewunmi OA, Markides CN. Thermo-economic and heat transfer optimization of working-fluid mixtures in a low-temperature organic Rankine cycle system. Energies 2019;9. https://doi.org/10.3390/en9060448.

[17] Van Erdeweghe S, Van Bael J, D'haeseleer W. Optimal configuration, design and control of a binary geothermal combined heat-and-power plant. Energy Convers Manag 2019;198. https://doi.org/10.1016/j.enconman.2019.111854.

[18] Van Erdeweghe S, Van Bael J, Laenen B, D'haeseleer W. Design and off-design optimization procedure for low-temperature geothermal organic Rankine cycles. Appl Energy 2019;242:716-31. https://doi.org/10.1016/j.apenergy.2019.03.142.

[19] Zhao Y, Wang J. Exergoeconomic analysis and optimization of a flash-binary geothermal $\begin{array}{llll}\text { power } & \text { system. } & \text { Appl } & \text { 2016;179:159-70. }\end{array}$ https://doi.org/10.1016/j.apenergy.2016.06.108.

[20] Lu X, Zhao Y, Zhu J, Zhang W. Optimization and applicability of compound power cycles for enhanced geothermal systems. Appl Energy 2018;229:128-41. https://doi.org/10.1016/j.apenergy.2018.07.033.

[21] Wang $\mathrm{L}, \mathrm{Li} \mathrm{H}, \mathrm{Bu} \mathrm{X}$. Multi-objective optimization of Binary Flashing Cycle (BFC) driven by geothermal energy. Appl Therm Eng 2020;166. https://doi.org/10.1016/j.applthermaleng.2019.114693.

[22] Clarke J, McLeskey JT. Multi-objective particle swarm optimization of binary geothermal power plants. Appl Energy 2015;138:302-14. https://doi.org/10.1016/j.apenergy.2014.10.072.

[23] Ren F, Wang J, Zhu S, Chen Y. Multi-objective optimization of combined cooling, heating and power system integrated with solar and geothermal energies. Energy Convers Manag 2019;197. https://doi.org/10.1016/j.enconman.2019.111866.

[24] Martínez-Gomez J, Peña-Lamas J, Martín M, Ponce-Ortega JM. A multi-objective optimization approach for the selection of working fluids of geothermal facilities: Economic, environmental and social aspects. J Environ Manage 2017;203:962-72. https://doi.org/10.1016/j.jenvman.2017.07.001.

[25] Sun Q, Wang Y, Cheng Z, Wang J, Zhao P, Dai Y. Thermodynamic and economic optimization of a double-pressure organic Rankine cycle driven by low-temperature heat source. Renew Energy 2020;147:2822-32. https://doi.org/10.1016/j.renene.2018.11.093.

[26] Tozlu A, Yosaf SA, Özcan H. Thermodynamic feasibility analysis of a newly modified absorption power cycle running with LiBr-water. Environ Prog Sustain Energy 2020. https://doi.org/10.1002/ep.13483.

[27] Zhang X, He M, Zhang Y. A review of research on the Kalina cycle. Renew Sustain Energy Rev 2012;16:5309-18. https://doi.org/10.1016/j.rser.2012.05.040.

[28] Sokolov M, Hershgal D, Aviv R. Part 1 . Systems characterization. Int J Refrig 
1990;13:351-6.

[29] Elbel S, Lawrence N. Review of recent developments in advanced ejector technology. Int J Refrig 2016;62:1-18. https://doi.org/10.1016/j.ijrefrig.2015.10.031.

[30] Habibollahzade A, Houshfar E, Ashjaee M, Ekradi K. Continuous power generation through a novel solar/geothermal chimney system: Technical/cost analyses and multi-objective particle swarm optimization. J Clean Prod 2020:124666. https://doi.org/10.1016/j.jclepro.2020.124666.

[31] Dai Y, Wang J, Gao L. Exergy analysis, parametric analysis and optimization for a novel combined power and ejector refrigeration cycle. Appl Therm Eng 2009;29:1983-90. https://doi.org/10.1016/j.applthermaleng.2008.09.016.

[32] Huang BJ, Chang JM, Wang CP, Petrenko VA. 1-D analysis of ejector performance. Int J Refrig 1999;22:354-64. https://doi.org/10.1016/S0140-7007(99)00004-3.

[33] Zhang K, Chen X, Markides CN, Yang Y, Shen S. Evaluation of ejector performance in an organic Rankine cycle. Appl Energy 2016;184:404-12. https://doi.org/10.1016/j.apenergy.2016.10.017.

[34] Behzadi A, Gholamian E, Ahmadi P, Habibollahzade A, Ashjaee M. Energy, exergy and exergoeconomic (3E) analyses and multi-objective optimization of a solar and geothermal based integrated energy system. Appl Therm Eng 2018;143:1011-22. https://doi.org/10.1016/j.applthermaleng.2018.08.034.

[35] Weinand JM, Kleinebrahm M, McKenna R, Mainzer K, Fichtner W. Developing a combinatorial optimisation approach to design district heating networks based on deep geothermal energy. Appl Energy 2019;251:113367. https://doi.org/10.1016/j.apenergy.2019.113367.

[36] Gholamian E, Zare V. A comparative thermodynamic investigation with environmental analysis of SOFC waste heat to power conversion employing Kalina and Organic Rankine Cycles. Energy Convers Manag 2016;117:150-61. https://doi.org/10.1016/j.enconman.2016.03.011.

[37] Besagni G, Mereu R, Inzoli F. Ejector refrigeration: A comprehensive review. Renew Sustain Energy Rev 2016;53:373-407. https://doi.org/10.1016/j.rser.2015.08.059.

[38] Hernández Martínez E, Avitia Carlos MCP, Cisneros Solís JI, Prieto Avalos MCM del C. Thermodynamic simulation and mathematical model for single and double flash cycles of Cerro Prieto geothermal power plants. Geothermics 2020;83:101713. https://doi.org/10.1016/j.geothermics.2019.101713.

[39] Rostamnejad Takleh H, Zare V. Employing thermoelectric generator and booster compressor for performance improvement of a geothermal driven combined power and ejector-refrigeration cycle. Energy Convers Manag 2019;186:120-30. https://doi.org/10.1016/j.enconman.2019.02.047.

[40] Shokati N, Ranjbar F, Yari M. A comparative analysis of rankine and absorption power cycles from exergoeconomic viewpoint. Energy Convers Manag 2014;88:657-68. https://doi.org/10.1016/j.enconman.2014.09.015.

[41] Mohammadzadeh Bina S, Jalilinasrabady S, Fujii H. Exergoeconomic analysis and optimization of single and double flash cycles for Sabalan geothermal power plant. Geothermics 2018;72:74-82. https://doi.org/10.1016/j.geothermics.2017.10.013. 
[42] Bejan A, Tsatsaronis G, Moran M. Thermal Design \& Optimization. John Wiley. 1996.

[43] Gholamian E, Habibollahzade A, Zare V. Development and multi-objective optimization of geothermal-based organic Rankine cycle integrated with thermoelectric generator and proton exchange membrane electrolyzer for power and hydrogen production. Energy Convers Manag 2018;174:112-25. https://doi.org/10.1016/j.enconman.2018.08.027.

[44] Habibollahzade A, Houshfar E. Improved performance and environmental indicators of a municipal solid waste fired plant through $\mathrm{CO} 2$ recycling: Exergoeconomic assessment and multi-criteria grey wolf optimisation. Energy Convers Manag 2020;225:113451. https://doi.org/10.1016/j.enconman.2020.113451.

[45] Parsopoulos KE, Vrahatis MN. Recent approaches to global optimization problems through Particle Swarm Optimization. Nat Comput 2002;1:235-306. https://doi.org/10.1023/A:1016568309421.

[46] Mehrabadi ZK, Boyaghchi FA. Thermodynamic, economic and environmental impact studies on various distillation units integrated with gasification-based multi-generation system: Comparative study and optimization. J Clean Prod 2019;241:118333. https://doi.org/10.1016/j.jclepro.2019.118333.

[47] Arpagaus C, Bless F, Uhlmann M, Schiffmann J, Bertsch SS. High temperature heat pumps: Market overview, state of the art, research status, refrigerants, and application potentials. Energy 2018;152:985-1010. https://doi.org/10.1016/j.energy.2018.03.166.

[48] Garcia-Hernando N, De Vega M, Soria-Verdugo A, Sanchez-Delgado S. Energy and exergy analysis of an absorption power cycle. Appl Therm Eng 2013;55:69-77. https://doi.org/10.1016/j.applthermaleng.2013.02.044.

[49] Novotny V, Kolovratnik M. Absorption power cycles for low-temperature heat sources using aqueous salt solutions as working fluids. Int J Energy Res 2017;41:952-75. https://doi.org/10.1002/er.3671.

[50] Le Lostec B, Galanis N, Millette J. Experimental study of an ammonia-water absorption chiller. Int. J. Refrig., vol. 35, Elsevier Ltd and IIR; 2012, p. 2275-86. https://doi.org/10.1016/j.ijrefrig.2012.05.012.

[51] Ruangtrakoon N, Thongtip T. An experimental investigation to determine the optimal heat source temperature for R141b ejector operation in refrigeration cycle. Appl Therm Eng 2020;170:114841. https://doi.org/10.1016/j.applthermaleng.2019.114841.

[52] Hogarth RA, Bour D. Flow Performance of the Habanero EGS Closed Loop. World Geotherm. Congr. 2015, 2015, p. 9.

[53] Shokati N, Ranjbar F, Yari M. Exergoeconomic analysis and optimization of basic, dualpressure and dual-fluid ORCs and Kalina geothermal power plants: A comparative study. Renew Energy 2015;83:527-42. https://doi.org/10.1016/j.renene.2015.04.069.

[54] Song J, Li X, Ren X, Tian H, Shu G, Gu C, et al. Thermodynamic and economic investigations of transcritical $\mathrm{CO} 2$-cycle systems with integrated radial-inflow turbine performance predictions. Appl Therm Eng 2020;165:114604. https://doi.org/10.1016/j.applthermaleng.2019.114604.

[55] Schuster S, Markides CN, White AJ. Design and off-design optimisation of an organic Rankine cycle (ORC) system with an integrated radial turbine model. Appl Therm Eng 2020:115192. https://doi.org/10.1016/j.applthermaleng.2020.115192. 
[56] Lukawski MZ, Anderson BJ, Augustine C, Capuano LE, Beckers KF, Livesay B, et al. Cost analysis of oil, gas, and geothermal well drilling. J Pet Sci Eng 2014;118:1-14. https://doi.org/10.1016/j.petrol.2014.03.012.

[57] Chamorro CR, Mondéjar ME, Ramos R, Segovia JJ, Martín MC, Villamañán MA. World geothermal power production status: Energy, environmental and economic study of high enthalpy technologies. Energy 2012;42:10-8. https://doi.org/10.1016/j.energy.2011.06.005.

[58] Zhang YJ, Li ZW, Guo LL, Gao P, Jin XP, Xu TF. Electricity generation from enhanced geothermal systems by oilfield produced water circulating through reservoir stimulated by staged fracturing technology for horizontal wells: A case study in Xujiaweizi area in Daqing Oilfield, China. Energy 2014;78:788-805. https://doi.org/10.1016/j.energy.2014.10.073.

[59] Dincer I, Rosen MA, Ahmadi P. Optimization of Energy Systems. vol. 53. Chichester, UK: John Wiley \& Sons, Ltd; 2017. https://doi.org/10.1002/9781118894484. 


\section{Appendix A}

935 The capital cost of the geothermal system is a function of drilling depth and also the reference 936 power for predicting surface installing, including production and reinjection wells. The drilling 937 cost (\$) is evaluated in this work through a function of depth (m) [56]:

$$
Z_{\text {drill }}=\left(1.72 \times 10^{-7} \times d^{2}+2.3 \times 10^{-3} \times d-0.62\right) \times 10^{6}
$$

The cost of surface installation (\$) is predicted as a function of the power output $(\mathrm{kW})$ of a conventional ORC-based geothermal system as [57,58]:

$$
Z_{\mathrm{SI}}=2000 \times \dot{W}_{\mathrm{ref}} \times \varphi
$$

The reference power output $(\mathrm{kW})$ is extracted after the curve fitting action considering the temperature of the geothermal well $\left({ }^{\circ} \mathrm{C}\right)$ and mass flow rate $(\mathrm{kg} / \mathrm{s})[2]$ :

$$
\dot{W}_{\text {ref }}=\dot{m}_{\text {geo }} \times\left(-67.06+0.736458 \times T_{\text {geo,wellhead }}\right)
$$

954 in which $\zeta$ refers to the temperature gradient at the geothermal site $\left(0.038{ }^{\circ} \mathrm{C} / \mathrm{m}\right.$ in this study $)$ and 955 $\theta$ denotes the correction coefficient required to predict the production fluid temperature, which is 956 lower than wellhead temperature [52]. Hence, in Eq. (A6), $\theta$ is considered equal to 0.868 to be 957 consistent with the real data by considering the temperature drop across the production well.

958 The geothermal brine temperature and the costs associated with surface installing and drilling, and 959 the present year considering CEPCI for 2010 and the present year.

Furthermore, the total capital cost (as a function of $d$, and the heat source temperature and flow rate) of the geothermal system is expressed as:

$$
Z_{\text {geo }}=Z_{\text {drill }}+Z_{\text {SI }}
$$

The temperature of geothermal wellhead and geothermal brine (heat source temperature in ${ }^{\circ} \mathrm{C}$ ) are also predicted considering the measured depth of the geothermal well $(d)$ in meters:

$$
\begin{gathered}
T_{\text {geo,wellhead }}=d \times \zeta \\
T_{\text {geo }}=d \times \zeta \times \theta
\end{gathered}
$$
overall cost are shown in Fig. A1 considering the borehole geothermal depth as a variable. The

It is noted that Eqs. (A2) and (A3) are valid for $d>3000 \mathrm{~m}$, and that they should be converted to 
960 highlighted area is the operating temperature of the proposed medium grade geothermal systems.

961 Producing geothermal brine with a temperature of higher than $200{ }^{\circ} \mathrm{C}$ is challenging due to the 962 limitations of drilling and operating and maintenance.

963

964
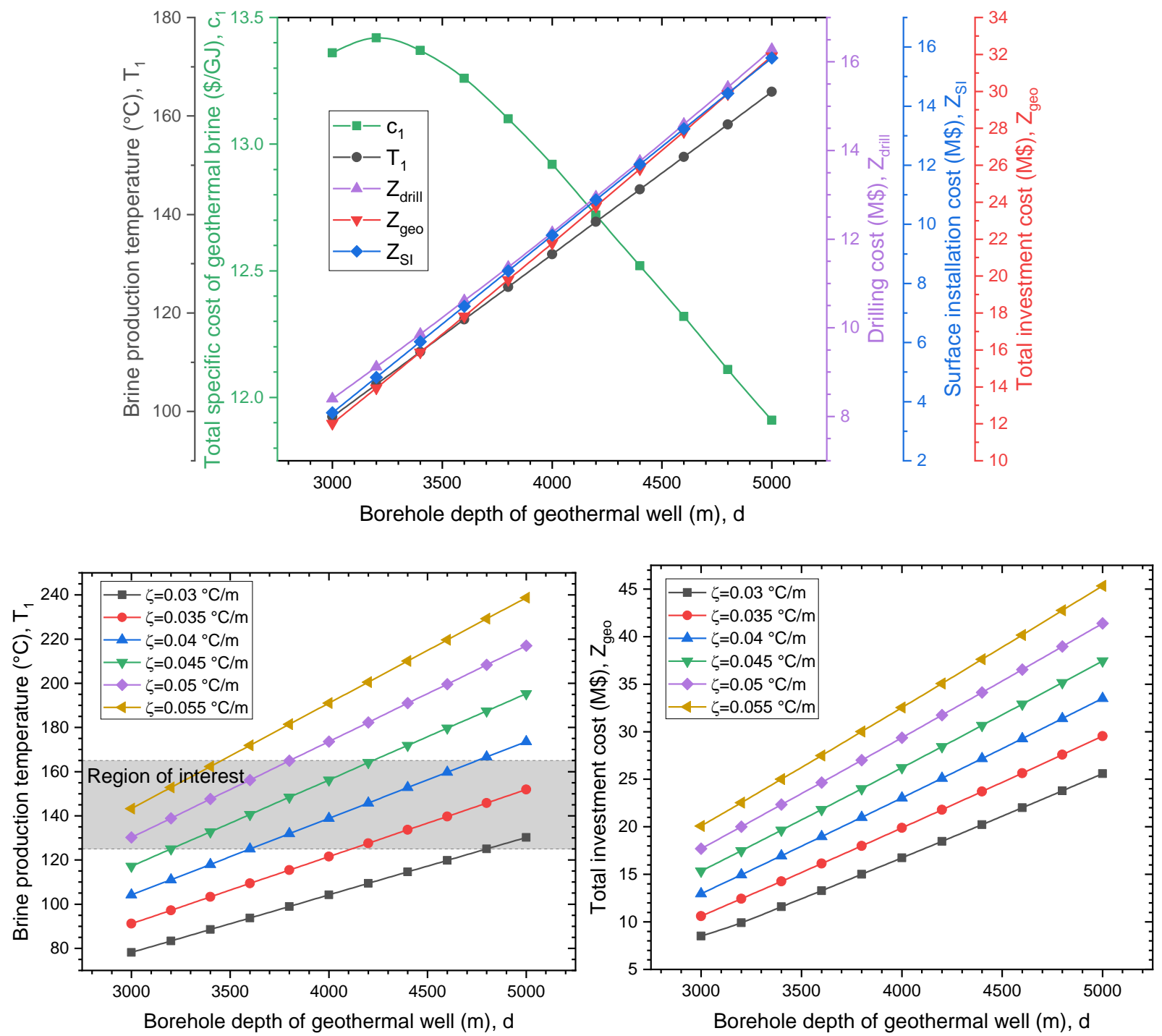

965

Fig. A1: Geothermal brine temperature and costs associated with the geothermal well

967

968 In addition, $M_{\mathrm{SP}}$ in the cost function of the separators in Configuration (b) and (c) is expressed as [19]:

969

$$
\log _{10}\left(M_{\mathrm{SP}}\right)=3.4974+0.4485 \times \log _{10}\left(V_{\mathrm{SP}}\left[\mathrm{m}^{3}\right]\right)+0.1074 \times\left(\log _{10}\left(V_{\mathrm{SP}}\left[\mathrm{m}^{3}\right]\right)\right)^{2}
$$




$$
V_{\mathrm{SP}}\left[\mathrm{m}^{3}\right]=\pi \times\left(3 D_{\mathrm{ip}}[\mathrm{m}]\right)^{2} \times \frac{7 \times D_{\mathrm{ip}}[\mathrm{m}]+4.5 \times D_{\mathrm{ip}}[\mathrm{m}]}{4}
$$

$$
D_{\mathrm{ip}}[\mathrm{m}]=\sqrt{4 \times \frac{A_{\mathrm{ip}}\left[\mathrm{m}^{2}\right]}{\pi}}
$$

$$
A_{\text {ip }}\left[\mathrm{m}^{2}\right]=\frac{\dot{m}_{\text {in }}[\mathrm{kg} / \mathrm{s}]}{v_{t}[\mathrm{~m} / \mathrm{s}] \times \rho_{\text {liquid }}\left[\mathrm{kg} / \mathrm{m}^{3}\right]}
$$

$$
v_{t}[\mathrm{~m} / \mathrm{s}]=0.069 \times \sqrt{\frac{\rho_{\text {liquid }}\left[\mathrm{kg} / \mathrm{m}^{3}\right]-\rho_{\text {vapour }}\left[\mathrm{kg} / \mathrm{m}^{3}\right]}{\rho_{\text {liquid }}\left[\mathrm{kg} / \mathrm{m}^{3}\right]}}
$$

974 Furthermore, $M_{\mathrm{SP}}^{\prime}$ in the cost function of the separators in Configuration (b) and (c) (see Table A3 975 and C4), and is given by [19]:

$$
M_{\mathrm{SP}}^{\prime}=\max \left\{\frac{\frac{\left(P_{\mathrm{in}, \mathrm{SP}}[\mathrm{bar}]+1\right) \times D_{\mathrm{ip}}[\mathrm{m}]}{2 \times\left(850-0.6 \times\left(P_{\mathrm{in}, \mathrm{SP}}[\mathrm{bar}]+1\right)\right)}+0.00315}{0.0063}, 1\right\}
$$

977 The heat exchanger areas required to calculate the capital cost of them is estimated from:

$$
\dot{Q}=U A \Delta T_{\mathrm{LMTD}}
$$

979 The value of heat transfer coefficient $(U)$ for different components are listed in Table A1.

980

981

Table A1: Values of heat transfer coefficient for different heat exchangers $\left[\frac{\mathrm{kW}}{\mathrm{m}^{2} \cdot \mathrm{K}}\right]$

\begin{tabular}{|c|c|c|c|c|c|}
\hline Generator & $\begin{array}{c}\text { Heat } \\
\text { exchanger }\end{array}$ & $\begin{array}{c}\text { Solution heat } \\
\text { exchanger }\end{array}$ & Absorber & Evaporator & Condenser \\
\hline 1.6 & 1.0 & 1.1 & 0.6 & 0.9 & 1.0 \\
\hline
\end{tabular}

982 
Table A2: Cost balance and cost functions for different components of Configuration (a)

\begin{tabular}{|c|c|c|c|}
\hline Component & $\begin{array}{c}\text { Cost balance and auxiliary } \\
\text { equations }\end{array}$ & Cost functions, Z (\$) [59] & $\begin{array}{l}\text { Ref. year } \\
\text { (CEPCI) }\end{array}$ \\
\hline $\begin{array}{l}\text { Geothermal } \\
\text { section }\end{array}$ & $\begin{array}{l}\dot{C}_{\text {water }}+\dot{Z}_{\text {geo }}=\dot{C}_{1} \\
c_{\text {water }}=0\end{array}$ & See Eqs. (A1) to (A6) & $\begin{array}{l}2010 \\
(550.8)\end{array}$ \\
\hline $\begin{array}{l}\text { Vapour } \\
\text { Generator } 1\end{array}$ & $\begin{array}{c}\dot{C}_{1}+\dot{C}_{5}+\dot{Z}_{\mathrm{VG} 1}=\dot{C}_{6}+\dot{C}_{10}+\dot{C}_{2} \\
c_{1}=c_{2}\end{array}$ & $Z_{\mathrm{VG} 1}=130 \times\left(A_{\mathrm{VG} 1}\left[\mathrm{~m}^{2}\right] / 0.093\right)^{0.78}$ & $\begin{array}{l}2005 \\
(468.2)\end{array}$ \\
\hline $\begin{array}{l}\text { Expansion } \\
\text { Valve } 2\end{array}$ & $\dot{C}_{19}+\dot{Z}_{\mathrm{EV} 2}=\dot{C}_{20}$ & $Z_{\mathrm{EV} 2}=0$ & - \\
\hline Pump 1 & $\begin{array}{c}\dot{C}_{\mathrm{w}, \mathrm{pu} 1}+\dot{C}_{3}+\dot{Z}_{\mathrm{pu} 1}=\dot{C}_{4} \\
c_{\mathrm{w}, \mathrm{pu} 1}=c_{\mathrm{w}, \mathrm{tu}}\end{array}$ & $Z_{\mathrm{pu} 1}=3540 \times\left(\dot{W}_{\mathrm{pu} 1}[\mathrm{~kW}]\right)^{0.71}$ & $\begin{array}{l}2010 \\
(550.8)\end{array}$ \\
\hline Pump 2 & $\begin{array}{c}\dot{C}_{\mathrm{w}, \mathrm{pu} 2}+\dot{C}_{14}+\dot{Z}_{\mathrm{pu} 2}=\dot{C}_{15} \\
c_{\mathrm{w}, \mathrm{pu} 2}=c_{\mathrm{w}, \mathrm{tu}}\end{array}$ & $Z_{\mathrm{pu} 2}=3540 \times\left(\dot{W}_{\mathrm{pu} 2}[\mathrm{~kW}]\right)^{0.71}$ & $\begin{array}{l}2010 \\
(550.8)\end{array}$ \\
\hline Absorber & $\begin{array}{c}\dot{C}_{9}+\dot{C}_{11}+\dot{C}_{12}+\dot{Z}_{\mathrm{abs}}=\dot{C}_{13}+\dot{C}_{3} \\
\frac{\dot{C}_{11}+\dot{C}_{9}}{\dot{E}_{11}+\dot{E}_{9}}=\frac{\dot{C}_{3}}{\dot{E}_{3}}, c_{12}=0\end{array}$ & $Z_{\mathrm{abs}}=130 \times\left(A_{\mathrm{abs}}\left[\mathrm{m}^{2}\right] / 0.093\right)^{0.78}$ & $\begin{array}{l}2005 \\
(468.2)\end{array}$ \\
\hline $\begin{array}{l}\text { Expansion } \\
\text { Valve } 1\end{array}$ & $\dot{C}_{8}+\dot{Z}_{\mathrm{EV} 1}=\dot{C}_{9}$ & $Z_{\mathrm{EV} 1}=0$ & - \\
\hline Turbine & $\begin{array}{c}\dot{C}_{10}+\dot{Z}_{\mathrm{tu}}=\dot{C}_{11}+\dot{C}_{\mathrm{w}, \mathrm{tu}} \\
c_{10}=c_{11}\end{array}$ & $Z_{\mathrm{tu}}=4405 \times\left(\dot{W}_{\mathrm{tu}}[\mathrm{kW}]\right)^{0.7}$ & $\begin{array}{l}2003 \\
(402.3)\end{array}$ \\
\hline $\begin{array}{l}\text { Solution Heat } \\
\text { Exchanger }\end{array}$ & $\begin{array}{c}\dot{C}_{4}+\dot{C}_{7}+\dot{Z}_{\mathrm{SHE}}=\dot{C}_{8}+\dot{C}_{5} \\
c_{8}=c_{7}\end{array}$ & $Z_{\mathrm{SHE}}=130 \times\left(A_{\mathrm{SHE}}\left[\mathrm{m}^{2}\right] / 0.093\right)^{0.78}$ & $\begin{array}{l}2005 \\
(468.2) \\
\end{array}$ \\
\hline Condenser & $\begin{array}{l}\dot{C}_{17}+\dot{C}_{25}+\dot{Z}_{\text {con }}=\dot{C}_{26}+\dot{C}_{18} \\
c_{17}=c_{18}, c_{25}=0\end{array}$ & $Z_{\text {con }}=130 \times\left(A_{\text {con }}\left[\mathrm{m}^{2}\right] / 0.093\right)^{0.78}$ & $\begin{array}{l}2005 \\
(468.2) \\
\end{array}$ \\
\hline Evaporator & $\begin{array}{c}\dot{C}_{20}+\dot{C}_{21}+\dot{Z}_{\mathrm{eva}}=\dot{C}_{22}+\dot{C}_{23} \\
c_{20}=c_{23}, c_{21}=0\end{array}$ & $Z_{\text {eva }}=130 \times\left(A_{\text {eva }}\left[\mathrm{m}^{2}\right] / 0.093\right)^{0.78}$ & $\begin{array}{l}2005 \\
(468.2)\end{array}$ \\
\hline Ejector & $\dot{C}_{16}+\dot{C}_{24}+\dot{Z}_{\mathrm{eje}}=\dot{C}_{17}$ & $Z_{\mathrm{EV} 2}=0$ & - \\
\hline Booster & $\begin{array}{c}\dot{C}_{\mathrm{w}, \mathrm{b}}+\dot{C}_{23}+\dot{Z}_{\mathrm{b}}=\dot{C}_{24} \\
c_{\mathrm{w}, \mathrm{b}}=c_{\mathrm{w}, \mathrm{tu}}\end{array}$ & $Z_{\mathrm{b}}=9624.2 \times\left(\dot{W}_{\mathrm{b}}[\mathrm{kW}]\right)^{0.46}$ & $\begin{array}{l}2005 \\
(468.2)\end{array}$ \\
\hline $\begin{array}{l}\text { Vapour } \\
\text { Generator } 2\end{array}$ & $\begin{array}{c}\dot{C}_{6}+\dot{C}_{15}+\dot{Z}_{\mathrm{VG} 2}=\dot{C}_{7}+\dot{C}_{16} \\
c_{7}=c_{6}\end{array}$ & $Z_{\mathrm{VG} 2}=130 \times\left(A_{\mathrm{VG} 2}\left[\mathrm{~m}^{2}\right] / 0.093\right)^{0.78}$ & $\begin{array}{l}2005 \\
(468.2)\end{array}$ \\
\hline
\end{tabular}


Table A3: Cost balance and cost functions for different components of Configuration (b)

\begin{tabular}{|c|c|c|c|}
\hline Component & $\begin{array}{c}\text { Cost balance and auxiliary } \\
\text { equations }\end{array}$ & Cost functions, $\mathbf{Z}(\mathbf{\$})[59]$ & $\begin{array}{l}\text { Ref. year } \\
\text { (CEPCI) }\end{array}$ \\
\hline $\begin{array}{l}\text { Geothermal } \\
\text { section }\end{array}$ & $\begin{array}{l}\dot{C}_{\text {water }}+\dot{Z}_{\text {geo }}=\dot{C}_{1} \\
c_{\text {water }}=0\end{array}$ & See Eqs. (A1) to (A6) & $\begin{array}{l}2010 \\
(550.8)\end{array}$ \\
\hline $\begin{array}{l}\text { Vapour } \\
\text { Generator }\end{array}$ & $\begin{array}{c}\dot{C}_{6}+\dot{C}_{2}+\dot{Z}_{\mathrm{VG}}=\dot{C}_{3}+\dot{C}_{17}+\dot{C}_{7} \\
c_{2}=c_{3}\end{array}$ & $Z_{\mathrm{VG}}=130 \times\left(A_{\mathrm{VG}}\left[\mathrm{m}^{2}\right] / 0.093\right)^{0.78}$ & $\begin{array}{l}2005 \\
(468.2)\end{array}$ \\
\hline $\begin{array}{l}\text { Expansion } \\
\text { Valve } 2\end{array}$ & $\dot{C}_{18}+\dot{Z}_{\mathrm{EV} 2}=\dot{C}_{19}$ & $Z_{\mathrm{EV} 2}=0$ & - \\
\hline Pump 1 & $\begin{array}{c}\dot{C}_{\mathrm{w}, \mathrm{pu} 1}+\dot{C}_{4}+\dot{Z}_{\mathrm{pu} 1}=\dot{C}_{5} \\
c_{\mathrm{w}, \mathrm{Pu} 1}=c_{\mathrm{w}, \mathrm{tu}}\end{array}$ & $Z_{\mathrm{pu} 1}=3540 \times\left(\dot{W}_{\mathrm{pu} 1}[\mathrm{~kW}]\right)^{0.71}$ & $\begin{array}{l}2010 \\
(550.8)\end{array}$ \\
\hline Pump 2 & $\begin{array}{c}\dot{C}_{\mathrm{w}, \mathrm{pu} 2}+\dot{C}_{15}+\dot{Z}_{\mathrm{pu} 2}=\dot{C}_{16} \\
c_{\mathrm{w}, \mathrm{pu} 2}=c_{\mathrm{w}, \mathrm{tu}}\end{array}$ & $Z_{\mathrm{pu} 2}=3540 \times\left(\dot{W}_{\mathrm{pu} 2}[\mathrm{~kW}]\right)^{0.71}$ & $\begin{array}{l}2010 \\
(550.8)\end{array}$ \\
\hline Absorber & $\begin{array}{l}\dot{C}_{16}+\dot{C}_{20}+\dot{C}_{27}+\dot{Z}_{\mathrm{abs}}=\dot{C}_{4}+\dot{C}_{28} \\
\frac{\dot{C}_{16}+\dot{C}_{20}}{\dot{E}_{16}+\dot{E}_{20}}=\frac{\dot{C}_{4}}{\dot{E}_{4}}, c_{27}=0\end{array}$ & $Z_{\mathrm{abs}}=130 \times\left(A_{\mathrm{abs}}\left[\mathrm{m}^{2}\right] / 0.093\right)^{0.78}$ & $\begin{array}{l}2005 \\
(468.2)\end{array}$ \\
\hline $\begin{array}{l}\text { Expansion } \\
\text { Valve } 1\end{array}$ & $\dot{C}_{12}+\dot{Z}_{\mathrm{EV} 1}=\dot{C}_{13}$ & $Z_{\mathrm{EV} 1}=0$ & - \\
\hline Turbine & $\begin{array}{l}\dot{C}_{9}+\dot{Z}_{\mathrm{tu}}=\dot{C}_{10}+\dot{C}_{\mathrm{w}, \mathrm{tu}} \\
c_{9}=c_{10}\end{array}$ & $Z_{\mathrm{tu}}=4405 \times\left(\dot{W}_{\mathrm{tu}}[\mathrm{kW}]\right)^{0.7}$ & $\begin{array}{l}2003 \\
(402.3)\end{array}$ \\
\hline $\begin{array}{l}\text { Solution Heat } \\
\text { Exchanger }\end{array}$ & $\begin{array}{l}\dot{C}_{11}+\dot{C}_{5}+\dot{Z}_{\mathrm{SHE}}=\dot{C}_{6}+\dot{C}_{12} \\
c_{12}=c_{11}\end{array}$ & $Z_{\mathrm{SHE}}=130 \times\left(A_{\mathrm{SHE}}\left[\mathrm{m}^{2}\right] / 0.093\right)^{0.78}$ & $\begin{array}{l}2005 \\
(468.2)\end{array}$ \\
\hline Condenser 1 & $\begin{array}{l}\dot{C}_{17}+\dot{C}_{23}+\dot{Z}_{\text {con } 1}=\dot{C}_{24}+\dot{C}_{18} \\
c_{17}=c_{18}, c_{23}=0\end{array}$ & $Z_{\mathrm{con} 1}=130 \times\left(A_{\mathrm{con} 1}\left[\mathrm{~m}^{2}\right] / 0.093\right)^{0.78}$ & $\begin{array}{l}2005 \\
(468.2) \\
\end{array}$ \\
\hline Condenser 2 & $\begin{array}{l}\dot{C}_{14}+\dot{C}_{25}+\dot{Z}_{\text {con2 }}=\dot{C}_{26}+\dot{C}_{15} \\
c_{14}=c_{15}, c_{25}=0\end{array}$ & $Z_{\text {con } 2}=130 \times\left(A_{\text {con }}\left[\mathrm{m}^{2}\right] / 0.093\right)^{0.78}$ & $\begin{array}{l}2005 \\
(468.2)\end{array}$ \\
\hline Evaporator & $\begin{array}{l}\dot{C}_{19}+\dot{C}_{21}+\dot{Z}_{\text {eva }}=\dot{C}_{22}+\dot{C}_{20} \\
c_{20}=c_{19}, c_{21}=0\end{array}$ & $Z_{\text {eva }}=130 \times\left(A_{\text {eva }}\left[\mathrm{m}^{2}\right] / 0.093\right)^{0.78}$ & $\begin{array}{l}2005 \\
(468.2) \\
\end{array}$ \\
\hline Mixer & $\dot{C}_{14}=\dot{C}_{13}+\dot{C}_{10}+\dot{Z}_{\mathrm{mix}}$ & $Z_{\text {mix }}=0$ & - \\
\hline $\begin{array}{l}\text { Heat } \\
\text { Exchanger }\end{array}$ & $\begin{array}{l}\dot{C}_{1}+\dot{C}_{7}+\dot{Z}_{\mathrm{HE}}=\dot{C}_{2}+\dot{C}_{8} \\
c_{1}=c_{2}\end{array}$ & $Z_{\mathrm{HE}}=130 \times\left(A_{\mathrm{SHE}}\left[\mathrm{m}^{2}\right] / 0.093\right)^{0.78}$ & $\begin{array}{l}2005 \\
(468.2) \\
\end{array}$ \\
\hline Separator & $\dot{C}_{8}+\dot{Z}_{\mathrm{SP}}=\dot{C}_{9}+\dot{C}_{11}$ & $Z_{\mathrm{SP}}=\left(2.52+1.82 \times M_{\mathrm{SP}}^{\prime}\right) \times M_{\mathrm{SP}}$ & $\begin{array}{l}2000 \\
(394.1)\end{array}$ \\
\hline
\end{tabular}


Table A4: Cost balance and cost functions for different components of Configuration (c)

\begin{tabular}{|c|c|c|c|}
\hline Component & $\begin{array}{c}\text { Cost balance and auxiliary } \\
\text { equations }\end{array}$ & Cost functions, Z (\$) [59] & $\begin{array}{l}\text { Ref. year } \\
\text { (CEPCI) }\end{array}$ \\
\hline $\begin{array}{l}\text { Geothermal } \\
\text { section }\end{array}$ & $\begin{array}{l}\dot{C}_{\text {water }}+\dot{Z}_{\text {geo }}=\dot{C}_{1} \\
c_{\text {water }}=0\end{array}$ & See Eqs. (A1) to (A6) & $\begin{array}{l}2010 \\
(550.8)\end{array}$ \\
\hline Separator 1 & $\begin{array}{l}\dot{C}_{2}+\dot{Z}_{\mathrm{SP} 1}=\dot{C}_{3}+\dot{C}_{4} \\
c_{3}=c_{4}\end{array}$ & $Z_{\mathrm{SP} 1}=\left(2.52+1.82 \times M_{\mathrm{SP} 1}^{\prime}\right) \times M_{\mathrm{SP} 1}$ & $\begin{array}{l}2000 \\
(394.1)\end{array}$ \\
\hline Separator 2 & $\begin{array}{l}\dot{C}_{5}+\dot{Z}_{\mathrm{SP} 2}=\dot{C}_{6}+\dot{C}_{9} \\
c_{6}=c_{9}\end{array}$ & $Z_{\mathrm{SP} 2}=\left(2.52+1.82 \times M_{\mathrm{SP} 2}^{\prime}\right) \times M_{\mathrm{SP} 2}$ & $\begin{array}{l}2000 \\
(394.1)\end{array}$ \\
\hline $\begin{array}{l}\text { Expansion } \\
\text { Valve } 2\end{array}$ & $\dot{C}_{4}+\dot{Z}_{\mathrm{EV} 2}=\dot{C}_{5}$ & $Z_{\mathrm{EV} 2}=0$ & - \\
\hline $\begin{array}{l}\text { Expansion } \\
\text { Valve } 1\end{array}$ & $\dot{C}_{1}+\dot{Z}_{\mathrm{EV} 1}=\dot{C}_{2}$ & $Z_{\mathrm{EV} 1}=0$ & - \\
\hline Pump & $\begin{array}{c}\dot{C}_{\mathrm{w}, \mathrm{pu}}+\dot{C}_{16}+\dot{Z}_{\mathrm{pu}}=\dot{C}_{17} \\
c_{\mathrm{w}, \mathrm{pu}}=c_{\mathrm{w}, \mathrm{tu}}\end{array}$ & $Z_{\mathrm{pu}}=3540 \times\left(\dot{W}_{\mathrm{pu}}[\mathrm{kW}]\right)^{0.71}$ & $\begin{array}{l}2010 \\
(550.8)\end{array}$ \\
\hline Turbine & $\begin{array}{l}\dot{C}_{3}+\dot{C}_{6}+\dot{Z}_{\mathrm{tu}}=\dot{C}_{7}+\dot{C}_{\mathrm{w}, \mathrm{tu}} \\
\frac{\dot{C}_{6}+\dot{C}_{3}}{\dot{E}_{6}+\dot{E}_{3}}=\frac{\dot{C}_{7}}{\dot{E}_{7}}\end{array}$ & $Z_{\mathrm{tu}}=4405 \times\left(\dot{W}_{\mathrm{tu}}[\mathrm{kW}]\right)^{0.7}$ & $\begin{array}{l}2003 \\
(402.3)\end{array}$ \\
\hline Condenser 1 & $\begin{array}{l}\dot{C}_{7}+\dot{C}_{19}+\dot{Z}_{\text {con } 1}=\dot{C}_{8}+\dot{C}_{20} \\
c_{7}=c_{8}, c_{19}=0\end{array}$ & $Z_{\mathrm{con} 1}=130 \times\left(A_{\operatorname{con} 1}\left[\mathrm{~m}^{2}\right] / 0.093\right)^{0.78}$ & $\begin{array}{l}2005 \\
(468.2)\end{array}$ \\
\hline Valve 1 & $\dot{C}_{8}+\dot{C}_{17}+\dot{Z}_{\mathrm{va} 1}=\dot{C}_{18}$ & $Z_{\mathrm{va} 1}=0$ & - \\
\hline Valve 2 & $\dot{C}_{12}+\dot{C}_{16}+\dot{Z}_{\mathrm{va} 2}=\dot{C}_{11}$ & $Z_{\mathrm{va} 2}=0$ & - \\
\hline Cooling set & $\begin{array}{l}\dot{C}_{9}+\dot{C}_{21}+\dot{Z}_{\mathrm{CS}}+\dot{C}_{23}=\dot{C}_{22}+ \\
\dot{C}_{24}+\dot{C}_{16} \\
c_{9}=c_{16}, c_{24}=c_{22}, c_{\mathrm{w}, \mathrm{b}}=c_{\mathrm{w}, \mathrm{tu}}\end{array}$ & $\begin{array}{l}\dot{Z}_{\mathrm{CS}}=\dot{Z}_{\text {eva }}+\dot{Z}_{\text {eje }}+\dot{Z}_{\text {con } 2}+\dot{Z}_{\mathrm{EV} 3}+\dot{Z}_{\text {com }} \\
Z_{\text {com }}=91562 \times\left(\dot{W}_{\text {com }}[\mathrm{kW}] / 455\right)^{0.67}\end{array}$ & $\begin{array}{l}\text { Refer to } \\
\text { each } \\
\text { component }\end{array}$ \\
\hline
\end{tabular}

